
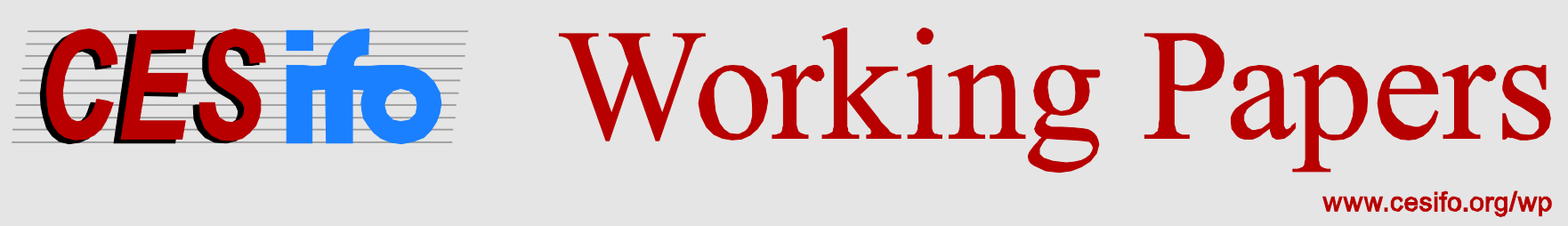

\title{
I Lie? We Lie! Why? \\ Experimental Evidence on a Dishonesty Shift in Groups
}

\author{
Martin G. Kocher \\ Simeon Schudy \\ Lisa Spantig
}

CESIFO WORKING PAPER NO. 6008

CATEGORY 13: BEHAVIOURAL ECONOMICS

JULY 2016

An electronic version of the paper may be downloaded

- from the SSRN website:

- from the RePEc website:

- from the CESifo website:

WwW.SSRN.com

www.RePEc.org

www.CESifo-group.org/wp 


\title{
I Lie? We Lie! Why? Experimental Evidence on a Dishonesty Shift in Groups
}

\begin{abstract}
Unethical behavior such as dishonesty, cheating and corruption occurs frequently in organizations or groups. Recent experimental evidence suggests that there is a stronger inclination to behave immorally in groups than individually. We ask if this is the case, and if so, why. Using a parsimonious laboratory setup, we study how individual behavior changes when deciding as a group member. We observe a strong dishonesty shift. This shift is mainly driven by communication within groups and turns out to be independent of whether group members face payoff commonality or not (i.e. whether other group members benefit from one's lie). Group members come up with and exchange more arguments for being dishonest than for complying with the norm of honesty. Thereby, group membership shifts the perception of the validity of the honesty norm and of its distribution in the population.
\end{abstract}

JEL-Codes: C910, C920, D030.

Keywords: dishonesty, lying, group decisions, communication, norms, experiment.

\author{
Martin G. Kocher \\ Ludwig-Maximilians-University Munich \\ Department of Economics \\ Germany / Munich \\ martin.kocher@Irz.uni-muenchen.de
}

\author{
Simeon Schudy \\ Ludwig-Maximilians-University Munich \\ Department of Economics \\ Germany / Munich \\ simeon.schudy@econ.Imu.de
}

\author{
Lisa Spantig* \\ Ludwig-Maximilians-University Munich \\ Department of Economics \\ Germany / Munich \\ Lisa.Spantig@econ.Imu.de
}

*corresponding author

July 14, 2016

We thank Johannes Abeler, Alexander Cappelen, Tim Cason, Urs Fischbacher, Anke Gerber, Uri Gneezy, Nicola Lacetera, Gerd Muehlheusser, Daniele Nosenzo, Andreas Roider, Devesh Rustagi, Shaul Shalvi, Ferdinand von Siemens, Matthias Sutter, Bertil Tungodden, Marie-Claire Villeval, Niklas Wallmeier and Ori Weisel as well as numerous seminar and conference participants at the Winter Experimental Social Sciences Institute (WESSI) at NYU Abu Dhabi, NHH Bergen, University of Chicago, University of Cologne, the BEGG Workshop at the University of Gothenburg, University of Hamburg, the London PhD Experimental Workshop (LPEx) at Royal Holloway, GATE at Lyon, University of Magdeburg, CAS Munich, LMU Munich, TU Munich, EBE Summer Meeting 2016, University of Nottingham, University of Melbourne, the Behavioral Spring School 2016 UC San Diego, the IAREP/SABE Meeting 2016, and Tilburg University for valuable comments and suggestions. Financial support is gratefully acknowledged from the Elite Network of Bavaria. 
"I did steal from Enron. We stole from Enron." The Enron Trial: Testimony of Andrew Fastow (former CFO of Enron)

"The conduct was fairly open and notorious, I would say. It was no great secret what we were doing." Christopher Loehr (former analyst for Enron)

\section{Introduction}

Groups and organizations sometimes fail to comply with a moral norm. They lie, they cheat, they are dishonest, they are corrupt, and they commit fraud. However, it is not organizations that take those decisions; it is individuals that are part of the organization. Can we thus explain undesired behavior in organizations simply by aggregating individual failures to comply with the norm? Or, are there other elements inherent to the organization or to its structure that can help us better understand how undesired behavior emerges? And, how does undesired behavior of individuals differ from behavior within or by an entire organization? While these are relevant questions, surprisingly little empirical evidence exists (Conrads et al., 2013; Sutter, 2009). This paper addresses these questions in a parsimonious setup that allows us to identify some of the potential reasons for collective failure to follow a moral norm or to comply with desired behavior.

Recent years have provided several prominent examples of unethical behaviors in groups and organizations. Fraudulent accounting methods and malpractice of groups of executive officers have led to the marked bankruptcies of WorldCom and Enron. More recently, it has been discovered that inter alia the German car producer Volkswagen has sold diesel cars with emissions certificates based on potentially faulty information. ${ }^{1}$ To improve emission test results Volkswagen has allegedly installed software in their diesel engines that could detect when the cars were on the test stand and adjust the engine performance accordingly. After investigations by the Environmental Protection Agency (EPA), newspaper articles say that "VW must have had a chain of management command that approved fitting cheating devices to its engines". ${ }^{2}$ However, it is not only for-profit firms that are involved in unethical behavior: there are cases of charities that commit embezzlement, sports

\footnotetext{
1 See http://www.telegraph.co.uk/finance/newsbysector/industry/11880433/How-has-Volkswagen-tricked-theUS-over-car-emissions.html, last downloaded: Feb 3, 2016.

2 See also http://www.bbc.com/news/business-34324772, last downloaded: Nov 29, 2015.
} 
organizations and executives that generate financial scandals or engage in morally and legally questionable practices in the context of doping, and sports teams that violate established norms. ${ }^{3}$

This study provides a twofold contribution. First, we implement a parsimonious laboratory setup to investigate whether groups (as our proxy for small organizations) are indeed more inclined to engage in dishonest or unethical behaviors than individuals, as casual observation and some previous results in the literature suggest (e.g., Chytilova and Korbel, 2014; Conrads et al., 2013; Gino et al., 2013; Muehlheusser et al., 2015; Sutter, 2009; Weisel and Shalvi, 2015). We find that the answer is affirmative. Individuals lie less frequently when deciding alone as compared to groups. Second, we offer and disentangle explanations for this "dishonesty shift". There are several candidate explanations: (i) a simple aggregation of individual inclinations as a consequence of aggregation rules (i.e. decision making procedures) within the group; (ii) the incentive structure inherent to many group decisions (oftentimes, all members share group payoffs equally and an individual deviation from either of the strategies - behaving dishonest or honest - can sometimes reduce payoffs for everyone dramatically); (iii) the decreased observability of one's actions within a group, potentially making the individual less accountable for their actions when they are group members; and (iv) the deliberation process inherent to group interaction involving, for instance, the exchange of arguments and learning about the strength and prevalence of a norm.

Our laboratory experiment uses a variant of the die-rolling task introduced by Fischbacher and Föllmi-Heusi (2013). Participants are asked to report the result of a die roll and their payoffs depends on their reports. ${ }^{4}$ Hence participants face a trade-off between being honest by reporting the true number and potentially forgoing a monetary profit (i.e. following the norm of honesty), on the one hand, and being dishonest and potentially earning more (i.e. violating the norm of honesty), on the other hand. We implement individual decision making situations and group decision making situations using an experimental design that allows us to study behavioral change (within subjects)

\footnotetext{
${ }^{3}$ See e.g. http://www.nytimes.com/2015/05/20/business/4-cancer-charities-accused-in-ftc-fraud-case.html, http://www.economist.com/blogs/gametheory/2015/09/fifa-corruption-scandal and http://www.bbc.com/sport/olympics/36542577, last downloaded: June 16, 2016.

${ }^{4}$ Our variant of the task is computerized and allows the experimenter to observe whether individuals misreport (for a similar idea see also Kajackaite and Gneezy, 2015). We explain the variant and the reasons for our design choice in more detail in Section 2.
} 
across several (between subjects) treatments. Our setup enables us to disentangle the explanations mentioned above.

In the die roll paradigm, a pure payoff maximizer would want to always report the number that yields the highest monetary payoff, regardless of the actual die roll. This is true for both the individual and the group decision making situation. If one assumes sufficiently high moral costs of lying, individuals might want to report truthfully, and the group outcome then depends on the aggregation of individual preferences. For instance, unanimity should lead to less lying than other aggregation mechanisms. Adding social image concerns, accountability considerations and changes in the perception of the norm, group interaction can drag the comparison between the indidivual and the group setting in any direction—-towards more or less dishonest behavior (Bénabou, 2013; Bénabou and Tirole, 2006, 2012; Falk and Tirole, 2016). Ultimately, the question of whether groups or individuals are more or less dishonest (and the causes and consequences of any potential shift from the individual to the group setting) can only be answered empirically.

A laboratory experiment has several advantages when it comes to the identification of the effects we are interested in: It allows us (i) to exogenously vary group membership and incentives for the group members to behave dishonestly; (ii) to observe individual behavior before individuals become members of a group as well as behavior/communication when the group decides; and (iii) to elicit individual beliefs about dishonest behavior of others. Naturally, there are limits to laboratory experiments. The task that we use is specific in the sense that it implies a zero fine for violating the norm of honesty. In bearing with the growing experimental literature on cheating and lying, this enables us to compare our results to exisiting studies that focus on individual decisions to lie. We implement group decisions in small groups with anonymous real-time chat interactions in order to keep as much experimental control as possible. These design choices lend themselves to extensions that bring the experimental setup closer to existing organizations with their hiearchies and with faceto-face interactions. Ultimately, field experiments are a desired methodology. Our aim here is to establish a set of explanations in a rigorosly controlled environment that feeds into the design of future studies, relaxing some of our restrictions systematically. 
The results from our setup reinforce the conclusion from the small existing literature: Groups are (much) more inclined to lie than individuals. Drawing on the older psychology literature that detected a shift from individuals to groups in terms of risky decisions making, coining it the "risky shift" (Pruitt and Teger, 1969; Teger and Pruitt, 1967), we refer to our finding as the "dishonesty shift". However, our main contribution is providing an explanation for this shift: The shift can neither be explained by a higher level of strategic sophistication of groups than individuals (Sutter, 2009), nor by a decreased observability of one's action as a group member. Both explanations are excluded by our design. Using appropriate treatment variations, we can also rule out that groups lie more than individuals because the other group members benefit from lying (Gino et al., 2013) or because group decisions require unanimity.

Our findings provide strong evidence for the importance of two mechanisms that drive the dishonesty shift and that are inherent to almost any group interaction: communication and learning about norm compliance. Communication exposes group members frequently to arguments in favor of violating the norm. The exchange of arguments and talking to people that argue in favor of violating the norm also changes the norm perception. We show that the expectation that other people (out-ofsample) lie increases significantly after the group interaction. A detailed analysis of the protocols from the group interaction suggests that groups lie more because communication enables them to justify dishonest behavior in a different way than individuals. Further we find that the dishonesty shift in groups is very strong such that the group composition (in terms of the number of initially dishonest group members) only weakly affects the extent of dishonesty in a group.

Understanding the mechanisms that contribute to the dishonesty shift is essential as it is a prerequisite for designing institutions and incentives that are conducive to norm compliance. Our results show that the availability and exchange of arguments that justify norm violating behavior is an important aspect. Such exchange is occurring naturally in groups where group members discuss how they should act. A next step could be to analyze potential mechanisms in the group interaction that are able to counterbalance this effect such as reminders of the norm or other related interventions.

The remainder of the paper is organized as follows: Section 2 describes the details of our experimental design and procedures, gives an overview of the literature, and provides behavioral 
predictions. In Section 3, we present the results from our experiment. Section 4 discusses our findings, and Section 5 concludes the paper.

\section{Experimental Design, Related Literature, and Predictions}

\subsection{Experimental Design and Procedures}

We use a variant of the die-rolling task introduced by Fischbacher and Föllmi-Heusi (2013), in which a pure payoff maximizer would want to always report the number that yields the highest monetary payoff (irrespective of the observed die roll). Experimental participants see a video of a die roll on their computer screen. The computer randomly chooses one out of six videos, each showing one possible outcome. Participants are informed about this, i.e. they know that the computer chooses each video with the same probability. The outcome of the die roll in the video is clearly visible for about 10 seconds. The participants' task is to enter the outcome shown in the video on the next screen, in a field stating “die number seen:___. Participants can enter any number between 1 and 6 . Importantly, payoffs depend on the number entered, not on the number actually seen. We use the same payoff structure as the original experiment, i.e. die numbers $\odot$ to $\odot$ yield one to five points respectively and die number yields zero points. As participants can enter any number between one and six, they have the possibility to report dishonestly. As we explicitly asked participants to report the number seen, we refer to deviating from truthful reporting as "dishonesty" or "lying" for the rest of the paper.

Die rolls shown in the video are chosen randomly by the computer and known by the experimenter such that participants cannot disguise their lies. ${ }^{5}$ Thus, in contrast to the original dierolling task, misreporting the die number in our experiment is clearly dishonest, but liars cannot disguise (for a similar task with observability see also Kajackaite and Gneezy, 2015). This is a desirable feature for our purposes for at least two reasons. First, the paradigm ensures that groups do

\footnotetext{
${ }^{5}$ Note that participants are informed about the experimental procedures. Hence, incomplete lying should occur rarely in our experiment.
} 
not lie more than individuals because it is easier to disguise lies in a group, as individual decisions are clearly observable by the experimenter in individual and group treatments. Second, the paradigm allows us to study in a within-subject design how individual behavior changes (i.e. when reporting alone as compared to when reporting after communication in a group). Further, the task is easy to understand, and we can thus exclude that groups have a significantly better understanding of the task. Nonetheless, full observability may affect the level of lying (as compared to no observability). Our main analysis focuses therefore on the relative comparison between individual decision making and group decision making (and not on the absolute levels of dishonest behavior). Interestingly, direct comparisons between situations of full observability by the experimenter and full privacy (Kajackaite and Gneezy, 2015) show minor differences in the absolute extent of lying, and similar conclusions can be drawn from comparable experiments that introduce an anonymous observer of the private die roll other than the experimenter (see, e.g., Baeker and Mechtel, 2015; Houser et al., 2016; Van de Ven and Villeval, 2015).

We implement a mixture of a within-subject and a between-subject design with three different between-subject treatments (Individual, GroupPC and GroupNoPC). Figure 1 illustrates the experimental design. Each treatment consists of three independent parts, for which instructions are displayed on-screen at the beginning of each part. One of the three parts is randomly determined to be payoff relevant at the end of the experiment, and this is common knowledge.

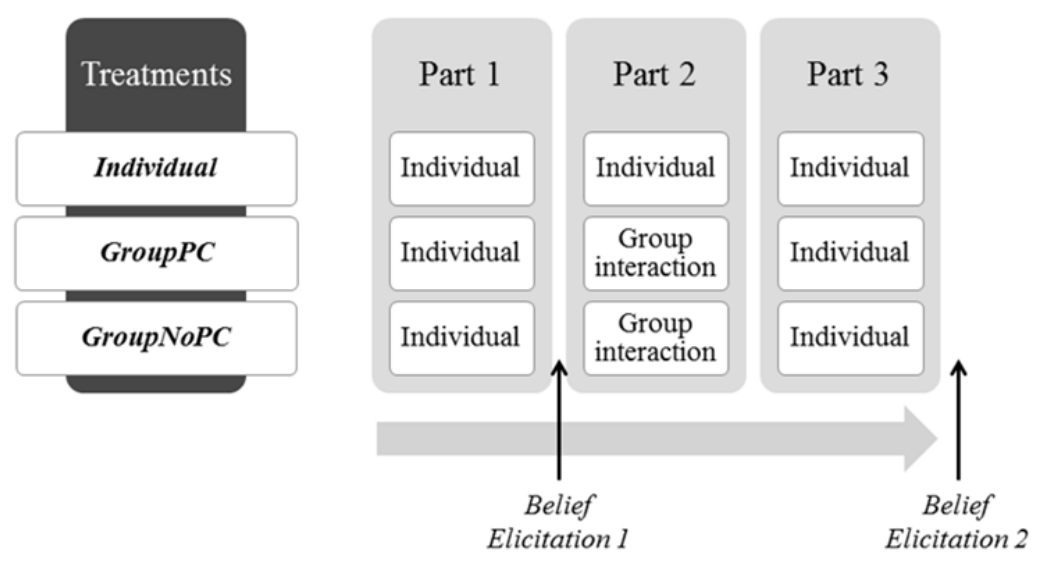

Figure 1: Experimental design and elicitation of beliefs. Note: Subjects are randomly allocated either to treatment Individual, GroupPC or GroupNoPC (between-subject) and participate in all three parts (within-subject). 
In the Individual treatment, participants make the same decision in each of the three parts: They see a video of a die roll on their screen and are asked to enter the die number seen on the next screen. In the two group treatments, the first part and the third part are equivalent to the decision in the same parts in Individual. In the second part of the group treatments, subjects decide in groups of three participants that are randomly assembled. Each participant in a group sees the same video (and this is common knowledge). After group members have seen the video, they have five minutes time to discuss in a group chat. The real-time chat allows for free-form communication without revealing one's identity (excluding the possibility of threats and side-payments). All three group members see all messages that are sent in the chat. The three members can also decide unanimously to leave the chat before its automated ending. After the chat, each participant privately enters the number (as in Individual), making each individual decision fully observable by the experimenter in all treatments. The two group treatments reflect different organizational structures as we vary whether or not group members earn a common payoff. In GroupPC, participants face a decision with payoff commonality. Each member of a group has to enter the same number to receive a payoff, and each participant receives the payoff that corresponds to the number entered. If entered numbers differ within a group, all group members receive zero payoffs. Such a protocol implements a strong unanimity component. In GroupNoPC, participants face no payoff commonality, i.e. they receive payoffs according to the number they enter, irrespective of the number entered by the other group members. GroupNoPC is thus identical to Individual except for the group chat after having seen the same video. It is important to notice that there is no pressure to contribute to the chat and that the content of the chat is totally up to the participants (i.e. they could talk about the weather, the weekend, and anything they wanted, except for revealing their identities in any way).

As the first part is identical in all treatments (and also decisions are very similar) we can use the between-subject comparisons between Individual and GroupPC as well as Individual and GroupNoPC in Part 2 to establish the difference in dishonest behavior between individual and groups (i.e. the potential existence of the dishonesty shift). The comparison between behavior GroupPC and GroupNoPC in Part 2 allows us to address the effect of payoff commonality, i.e. the relevance of the 
other-regarding concerns argument in group decision making that involves a trade-off between payoff maximization and norm compliance. ${ }^{6}$

To observe whether the group chat changes participants' beliefs about others' behavior in terms of (dis)honesty, we elicit our participants' beliefs about the lying behavior in a past experiment (i.e. in the baseline condition of Fischbacher and Föllmi-Heusi, 2013). Following Fischbacher and FöllmiHeusi (2013), we elicit participants' beliefs about the distribution of payoffs. We inform our participants that they have to guess the behavior of other participants in a similar, previously run experiment (from now on "reference experiment"). Participants then guess the shares of participants that earned a specific payoff, i.e. 0 points, 1 point, 2 points, etc. Implicitly, the distribution provides the belief about honesty of similar decision makers. Participants earn five euros if they guessed all shares correctly. For every percentage point deviation from the correct shares we reduce participants' payoff by 0.04 euros. The minimum payoff they can earn in the belief elicitation task is 0.50 euros. To avoid potential problems of hedging, we randomly selected one of the two belief elicitation tasks at the end of the experiment to be payoff-relevant. ${ }^{7}$ Two aspects of the belief elicitation are important: First, the way we elicit beliefs makes it clear to participants that we ask them about past behavior of other participants, which is exogenous to the current experiment. Second, we make clear that the data from the reference experiment is exactly the same for Belief Elicitation 1 and Belief Elicitation 2. Hence, changes in elicited values indicate a change in beliefs that can only be explained by the experience in our experiment.

During our experiment, each participant sat at a randomly assigned, separated PC terminal and received a copy of printed general instructions upfront. ${ }^{8}$ These informed participants that the experiment consists of three independent parts (one randomly determined to be payoff-relevant at the end) and that the specific instructions for each part would be displayed at the beginning of each part on the participants' computer screen. A set of on-screen control questions ensured the understanding

\footnotetext{
${ }^{6}$ As our focus is on how lying behavior changes in groups as compared to individuals (Part 1 and 2) we do not provide a detailed analysis of the data from Part 3. Lying rates in Part 3 are high (71.8 in Individual, 82.1 in GroupPC, and 84.6 in GroupNoPC) and do not differ significantly across treatment.

${ }^{7}$ This random draw was independent of the random draw that determined payoffs for the lying task.

${ }^{8}$ The translated version of the instructions can be found in the online appendix (section C).
} 
of the game in each part. ${ }^{9}$ Each part started only after all subjects answered the control questions correctly. Participants could fail the control questions repeatedly and were allowed to ask the experimenter to provide an explanation. No form of communication was allowed during the experiment (except through the computerized chat environment in the group treatments). We conducted all sessions at the Munich Experimental Laboratory for Economic and Social Sciences (MELESSA) at LMU Munich. The MELESSA subject pool includes undergraduate and graduate students of all fields of study. The data for the main treatments was collected over 14 sessions between June and September 2015, with 273 participants in total (39 in Individual, 117 in GroupPC, and 117 in GroupNoPC). ${ }^{10}$ In the first two sessions, the computer randomly selected for each group in each part one out of the six possible videos of a die roll with equal probability. To increase statistical power and simplify non-parametric comparisons between treatments, we used these randomly determined sets of videos in the later sessions, such that in each part, the same die rolls were observed in each treatment. This procedure ensures that die rolls displayed are held constant across treatments, and we can compare the number of dishonest reports across treatments, holding the monetary costs of being honest constant. In our main analysis we compare the individual-level data of the control treatment to the collapsed data from the group treatments. ${ }^{11}$ Hence we have 39 statistically independent observations in each treatment.

Participants received a show-up fee of four euros that was added to the earnings from the experiment. Subjects could earn points, where one point was equal to two euros. The experiment took about an hour. The average income (including the show-up fee) amounts to 14.62 euros. The experiment was programmed and conducted using z-Tree (Fischbacher, 2007). We recruited

\footnotetext{
${ }^{9}$ As Part 3 was identical to Part 1, we displayed the control questions in Part 3 again, but showed the subjects the correct answers. The correlation between the number of times participants failed to answer the control questions correctly and the extent of (dis)honesty is small and fails to be statistically significant (Spearman's Rho, individual level data, Part 1: $-0.0963, \mathrm{p}=0.112$; Part 2: $-0.027, \mathrm{p}=0.663$ ). Hence, problems in understanding the experimental procedures are unlikely to explain variation in lying behavior between treatments in the experiment.

${ }^{10}$ Two sessions $(\mathrm{n}=39)$ of an additional control treatment (IndividualDeliberation) that allows us to look into one of the potential explanations were conducted in February 2016 (see also Section 4).

${ }^{11}$ We collapse the group treatment data on the behavior of the group median to ease applicability of nonparametric tests. Using group averages (where applicable) yields very similar results.
} 
participants using the online recruiting system ORSEE (Greiner, 2015) and excluded all subjects with previous experience in die rolling tasks or other similar experiments.

\subsection{Related Literature and Behavioral Predictions}

In our task, a rational selfish individual would want to report a “国”, regardless of the actual die roll. This is true for both the individual and the group decision making situation. The experimental literature in economics has shown that frequently individuals are willing to forego monetary benefits to behave honestly in such situations (see e.g. Abeler et al., 2014; Cappelen et al., 2013; Erat and Gneezy, 2012; Fischbacher and Föllmi-Heusi, 2013; Glätzle-Rützler and Lergetporer, 2015; Gneezy, 2005; Gneezy et al., 2013; Kajackaite and Gneezy, 2015; Kröll and Rustagi, 2016; Lundquist et al., 2009; Mazar et al., 2008). This contrasts behavior of purely self-interested payoff maximizers but is in line with models that incorporate moral costs of lying.

Recent work has started to investigate dishonesty in groups (e.g. Baeker and Mechtel, 2015; Chytilova and Korbel, 2014; Conrads et al., 2013; Muehlheusser et al., 2015; Sutter, 2009). The group decision making setup adds several dimensions to the problem. First, it adds the aggregation problem of individual preferences in case they are not completely aligned. Second, the group setup might make social aspects more relevant: hiding behind the other group members (accountability), payoff commonality and the need to coordinate, and social imagine concerns. Based on existing work, we may expect groups to lie more than individuals for at least three reasons: First, groups may generally apply significantly higher levels of reasoning than individuals (Kocher et al., 2006; Kocher and Sutter, 2005). Thus, groups may lie more as they have a better understanding of the game (Sutter, 2009). Second, groups may lie more, as it can be easier to disguise lying in groups than individual lies (Conrads et al., 2013). Both arguments should play a minor role in the context of our experimental design. The task is easy, and individual choices are perfectly observable by the experimenter in all treatments. Third, recent work suggests that groups could lie more because others may benefit as well from dishonest behavior (Gino et al., 2013; Weisel and Shalvi, 2015; Wiltermuth, 2011). The comparison between treatments GroupPC and GroupNoPC will address this argument explicitly. 
However, there are also good arguments against a stronger prevalence of lying among groups than among individuals or arguments that do not provide a signed prediction. First, social image concerns should be stronger when deciding in a group (see e.g. Bénabou, 2013; Bénabou and Tirole, 2006; Bénabou and Tirole, 2012). Second, changes in the perception of the norm in the course of the group interaction can drag the comparison between the indidivual and the group setting towards more or less dishonest behavior. To be conservative, we formulate the following null hypotheses:

$H_{0}^{1}$ : The shares of dishonest reports in Part 2 in Individual and GroupPC do not differ. $H_{0}^{2}$ : The shares of dishonest reports in Part 2 in GroupPC and GroupNoPC do not differ.

\section{$3 \quad$ Results}

We structure the results section as follows. First, in Section 3.1, we present results on whether groups lie more than individuals, and if so, whether dishonesty becomes more prevalent in groups due to payoff commonality and how group communication affects beliefs about norm compliance (out-ofsample). Then we analyze the effect of group composition in terms of Part 1 liars on group decisions (in Section 3.2). In Section 3.3, we provide a content analysis of the group chat. Section 3.4 provides additional robustness tests for our main results, controlling for personal characteristics of group members.

\subsection{Dishonesty Shift and Payoff Commonality}

Figure 2 illustrates participants' reporting behavior in Part 1, 2 and 3 by showing the numbers subjects reported (y-axis) conditional on the number they have seen (x-axis). Note that the figure organizes the axis based on points, which means that the "国” is shown at the origin. It is clear that we observe either honest reporting (dots along the $45^{\circ}$ line) or dishonest reporting by stating the number that yields the highest returns, i.e. “因”. ${ }^{12}$ The fraction of subjects misreporting in Part 1 ranges from 31 to

\footnotetext{
${ }^{12}$ The absence of incomplete lying is in line with the fact that there is nothing to disguise in our experiment (in contrast to Fischbacher and Föllmi-Heusi, 2013). It also confirms the findings of a similar treatment in Kajackaite and Gneezy (2015) that uses an "observed game".
} 
41 percent and - as Part 1 is identical for all treatments - does not differ significantly between treatments (Fisher's exact tests, GroupPC vs. Individual: p=0.810; GroupNoPC vs. Individual: p=0.479; and GroupPC vs. GroupNoPC: p=0.816). In Part 2, we observe significantly more lying in GroupPC than in Individual. The fraction of dishonest reports amounts to 89.7 percent in GroupPC whereas in Individual, 61.5 percent of participants misreport their number (Fisher's exact test, $\mathrm{p}=0.007)$. The results are qualitatively similar and remain statistically significant if we exclude

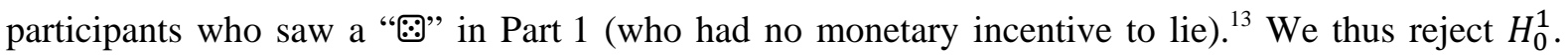

Treatments

Individual

GroupNoPC
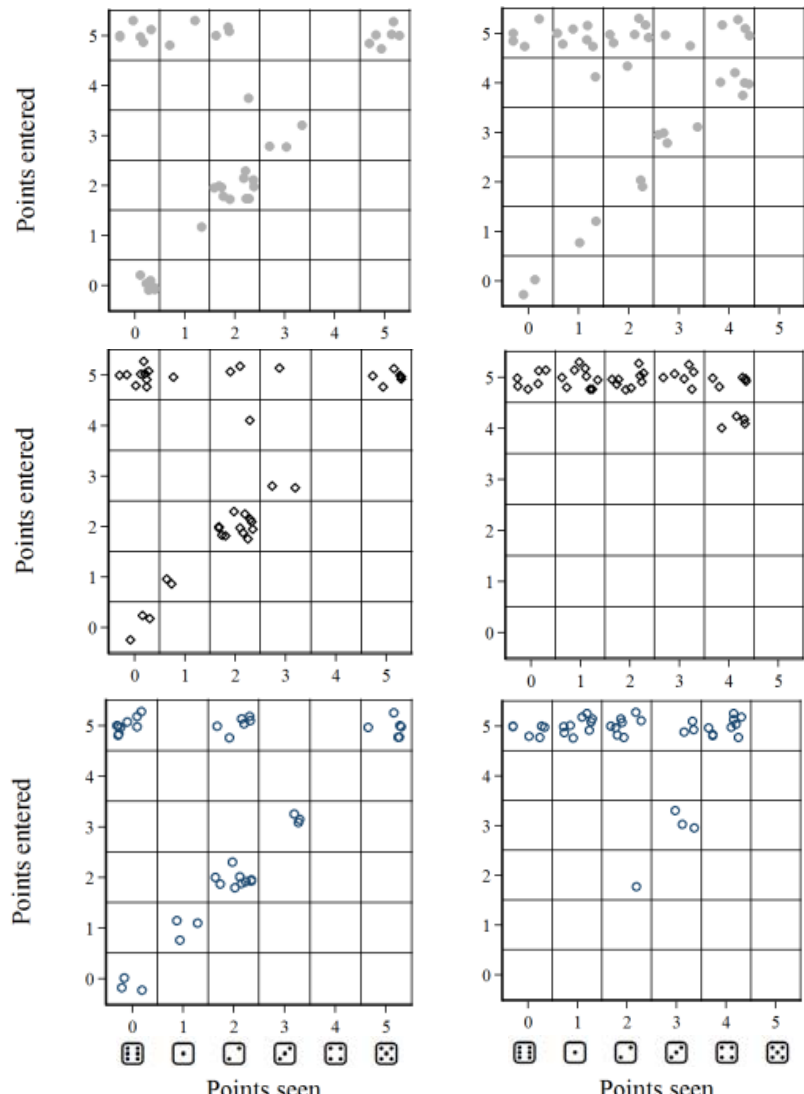

Points seen
Part 3
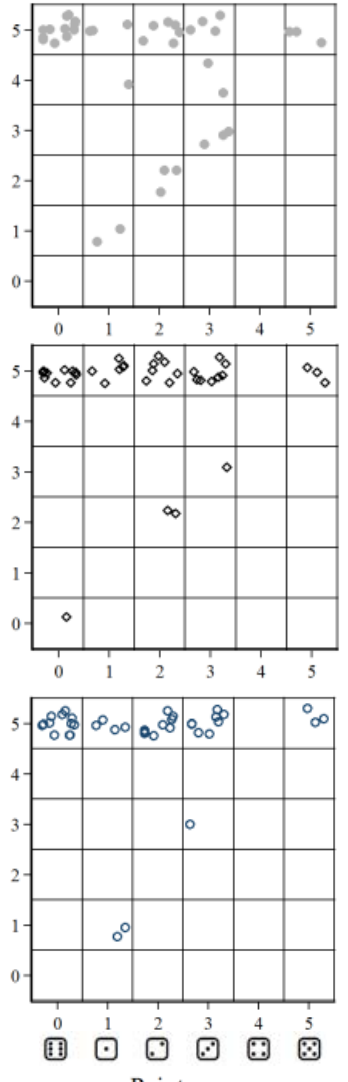

Points seen

Figure 2: Die numbers seen and die numbers reported across treatments and parts (jittered) Note: In Individual, each dot represents one participant's reported number. In the group treatments, each dot represents the median number reported in a group. For readability the figure shows points (i.e. a die role of "国” is shown as 0 points).

${ }^{13}$ As a robustness test, we conducted all analyses reported in this paper also for a subsample that excludes participants who have seen a "을 in Part 1 . All results remain unchanged, i.e. they are qualitatively similar and differences remain significant, except for one result concerning the influence of the group composition on misreporting (which we discuss in Section 3.2). The online appendix (section B1) provides more details. 
In GroupNoPC, the fraction of dishonest reports amounts to 86.3 percent which is also significantly larger than the 61.5 percent in Individual (Fisher's exact test, $\mathrm{p}=0.007$ ) but does not differ significantly from the median of misreports in GroupPC (Fisher's exact test, $\mathrm{p}=1.00$ ). Hence, we cannot reject $H_{0}^{2}$. We summarize our findings in Result 1.

Result 1: Groups lie significantly more than individuals, irrespective of payoff commonalities.

Both payoff commonality and mere communication in GroupNoPC strongly foster coordination. In GroupPC, all 39 groups coordinate, i.e. all members enter the same number (see Table 1). In GroupNoPC, group members do not have to enter the same number to receive a positive payoff and, as compared to GroupPC, slightly less members do so (Fisher's exact test, $\mathrm{p}=0.025$ ). Still, 33 out of 39 groups coordinate after the group chat. In five out of the six remaining groups, two out of three members report dishonestly. To compare coordination in the group treatments with a benchmark, we simulate “coordination” behavior in Individual based on participants' actual reporting from Part 2 in Individual. $^{14}$

Table 1: Coordination among group members in Part 2

\begin{tabular}{lccccc}
\hline \hline & Coordination & $\begin{array}{c}\text { Number of } \\
\text { dishonest } \\
\text { reports }\end{array}$ & $\begin{array}{c}\text { Simulated } \\
\text { groups }\end{array}$ & $\begin{array}{c}\text { Group } \\
\text { PC }\end{array}$ & $\begin{array}{c}\text { Group } \\
\text { NoPC }\end{array}$ \\
\hline & Yes (all honest) & 0 & 2 & 4 & 3 \\
$\begin{array}{l}\text { Lying decision } \\
\text { of individuals } \\
\text { in Part 2 }\end{array}$ & No & 1 & 11 & 0 & 1 \\
& No (all dishonest) & 3 & 17 & 0 & 5 \\
\cline { 2 - 6 } & Yes (all dishonest) & 3 & 6 & 35 & 30 \\
\hline $\begin{array}{l}\text { Coordination } \\
\text { rate }\end{array}$ & 2 & 39 & 39 & 39 \\
\hline \hline $\begin{array}{l}\text { Note: Simulated groups are based on Part 2 decisions in Individual. Note that for three simulated groups all } \\
\text { group members lie, but they still do not coordinate (due to partial lying by one member). }\end{array}$
\end{tabular}

\footnotetext{
${ }^{14}$ Following the literature on peer effects (Falk and Ichino, 2006), we randomly place three different individuals who have seen the same number (i.e. have similar costs of lying) into a group and repeat this procedure until we have generated the same number of groups that have seen the particular number in each of the two group treatments. For this set of groups, we check how many groups coordinate. In total, we simulate 500 sets of groups in this way and take the average over how many groups coordinate in each simulated set.
} 
As can be seen in Table 1, actual coordination rates in both GroupPC and GroupNoPC are significantly higher than coordination in simulated groups in Individual (Fisher's exact tests, $\mathrm{p}<0.001$ for the two comparisons). We summarize our findings in Result 2.

Result 2: Communication increases coordination.

Next, we focus on how the group interaction affects participants' beliefs about reporting behavior of subjects in a reference experiment. We elicited these beliefs once before Part 2 and once after Part 3. Figure 3 shows how participants' beliefs about reporting behavior of subjects in the reference experiment changed from Part 1 to Part 3 for the three treatments. In Individual, the expected share of subjects reporting a "®i in the reference experiment increases from Part 1 to Part 3 by 12.8 percentage points in Individual whereas the expected fractions of subjects reporting “国” and “” decrease. In contrast, when participants interacted in a group, their beliefs change to a much larger extent. The expected share of subjects reporting a "®o" in the reference experiment increases by 35.7 (31.3) percentage points in GroupPC (GroupNoPC). We thus observe a significant change in the skewness of beliefs on the reported numbers in the reference experiments for group treatments (Wilcoxon signed-rank exact test, GroupPC: $\mathrm{p}=0.002$; GroupNoPC: $\mathrm{p}<0.001$ ) but not for Individual (Wilcoxon signed-rank exact test, $\mathrm{p}=0.735) .{ }^{15}$ Consequently, the difference in the belief changes is larger in the group treatments (Kolmogorov-Smirnov exact test, GroupPC vs. Individual: p=0.090, GroupNoPC vs Individual: p=0.006). We conclude with Result 3.

Result 3: Group communication decreases beliefs about honest behavior of other participants in a reference experiment.

\footnotetext{
${ }^{15}$ We calculate the non-parametric skewness $\mathrm{S}_{\mathrm{it}}=(\mu-v) / \sigma$ measure for each individual's belief distribution and compare this measure for Part 1 and Part 3, where $\mu$ represents the mean, $v$ the median, and $\sigma$ the standard deviation. The tests for the group treatments uses group-level data (collapsed on the median).
} 


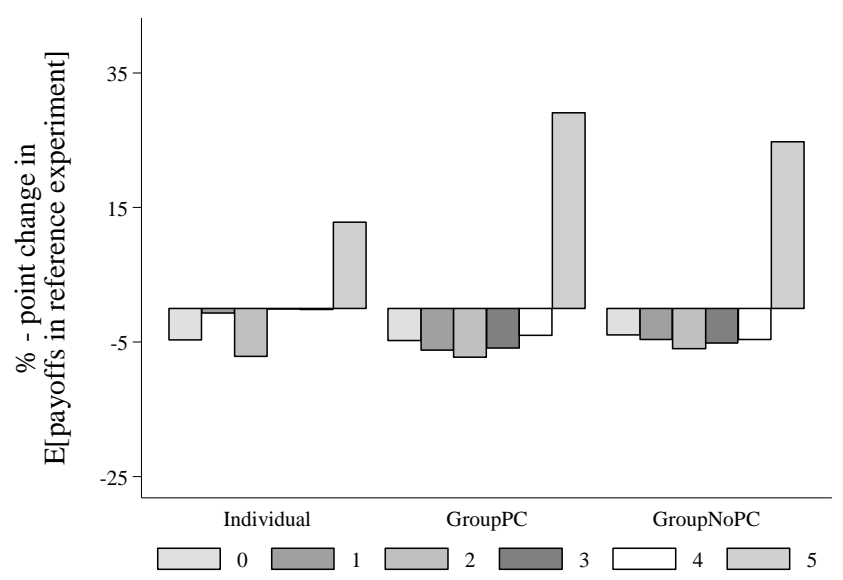

Figure 3: Change in beliefs about reported payoffs in a reference experiment in terms of the share of participants that reported a payoff $\pi \epsilon\{0 ; 1 ; 2 ; 3 ; 4 ; 5\}$

\subsection{The Role of (Dis)honest Individuals in Groups}

We document a strong dishonesty shift in both group treatments casting doubt on the idea that behavior in groups is a simple result of individual preference aggregation due to payoff commonalities. Our experimental design allows us to shed more light on how dishonesty evolves in groups. By studying how the group composition (in terms of participants' individual tendency to report dishonestly in Part 1) affects the propensity to lie in Part 2. Figure 4 displays the share of group members reporting dishonestly in Part 2 conditional on the number of group members who misreported in Part 1. Surprisingly, the group composition does (if at all) play a weak role for dishonest reporting in Part 2 of the group treatments (Spearman's Rho: 0.135, p=0.237; Fisher's exact test $\mathrm{p}=0.489$ ). Even in groups consisting of three previously honest individuals, the vast majority decides to report dishonestly after the group interaction. Only when excluding those participants who have seen a $\because$ in Part 1, i.e. those for whom we do not know whether they would have reported dishonestly if they had seen a different number, we find weak evidence for differences in lying levels across different group compositions (Spearman's Rho $=0.253$, $\mathrm{p}=0.041$, Fisher's exact test $\mathrm{p}=0.213$ ). ${ }^{16}$ We summarize this finding in Result 4.

Result 4: Group composition in terms of lying in Part 1 affects lying in groups in Part 2 only weakly. It does not matter for GroupPC, and it matters weakly for GroupNoPC.

\footnotetext{
${ }^{16}$ For a more detailed analysis, see the online appendix (section B1).
} 


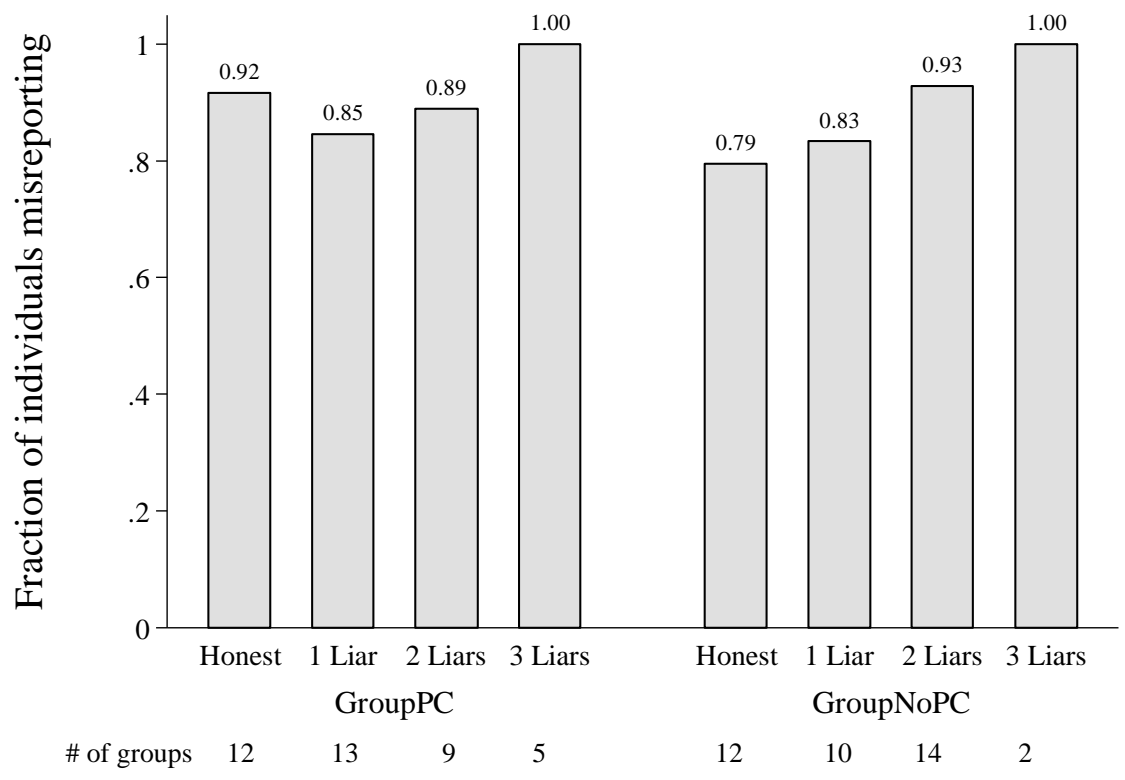

Figure 4: Dishonest reporting across treatments conditional on the number of group members who misreported in Part 1.

\subsection{The Impact of Arguments Used in the Group Chat}

Results 1 to 3 show that communication has a detrimental effect on honest reporting behavior as well as on beliefs about others' honesty. To understand how the group chat affected reporting behavior, four research assistants (to whom the purpose of the study was unknown) independently coded each of the chats using a codebook with a predefined set of variables of interest. ${ }^{17}$ Naturally, some coders interpreted the chat protocols differently than others. To obtain reliable values for our variables of interest which, on the one hand, reflect the majority opinion of coders and are, on the other hand, not systematically biased to extreme values we used the median value for each variable of interest if coders disagreed. ${ }^{18}$ We observe on average 17.45 (std dev. $=8.76$ ) messages in our 78 groups, and chats last about 162 seconds (std dev. = 85.7). ${ }^{19}$ First, we examine which arguments are used and whether their use is intended to encourage honest or dishonest behavior. Then, we analyze the impact of these arguments on participants' actions.

\footnotetext{
${ }^{17}$ The codebook including the complete list of variables can be found in the online appendix (section D).

${ }^{18}$ Note that in 83 percent of cases at least three coders agreed on a value of a variable. Our results are robust to using average ratings instead of medians.

${ }^{19}$ Chats in GroupNoPC are longer than in GroupPC, both in terms of messages and duration (Wilcoxon ranksum exact tests, $\mathrm{p}=0.003$ and $\mathrm{p}<0.001$, respectively). Otherwise we find only minor differences in the structure and the content of the chats (as discussed below).
} 
Table 2: Number of groups using honest and dishonest arguments

\begin{tabular}{cccc}
\hline \multicolumn{4}{c}{$\begin{array}{c}\text { Arguments for } \\
\text { Dishonesty mentioned }\end{array}$} \\
\hline $\begin{array}{c}\text { Arguments for } \\
\text { Honesty mentioned }\end{array}$ & Yes & No & $\sum$ \\
\hline Yes & 13 & 6 & 19 \\
No & 27 & 32 & 59 \\
$\Sigma$ & 40 & 38 & 78 \\
\hline \hline
\end{tabular}

In 51 percent of our groups (40 out of 78) arguments for dishonesty are explicitly mentioned, whereas only 19 groups make arguments for honesty (see Table 2). Thus, dishonest arguments are made more frequently than honest arguments $\left(\chi^{2}\right.$-test, $\left.\mathrm{p}=0.086\right)$. The average share of messages containing arguments for dishonest behavior (i.e. the number of messages using arguments for dishonest reporting in a group divided by the number of messages including arguments for honest and dishonest reporting in the group) amounts to 43.4 percent and is significantly higher than the share of honest messages (16 percent; within group comparison, Wilcoxon signed-rank exact test, $\mathrm{p}<0.001$ ). First, suggestions on which number to report are made by both honest and dishonest individuals (classified according to their behavior in Part 1) in equal proportion. Comparing whether groups make no argument for (dis)honesty or at least one argument we do not observe any significant differences between GroupPC and GroupNoPC concerning dishonest arguments $\left(\chi^{2}\right.$-test, $\left.\mathrm{p}=0.365\right)$. More groups without payoff commonality send, however, at least one argument for honesty $(\mathrm{p}=0.065)$. We summarize our findings in Result 5.

Result 5: Arguments for dishonesty occur significantly more frequently than arguments for honesty, irrespective of payoff commonality.

Let us now turn to what arguments are made in favor of honest and dishonest reporting and how these arguments relate to actual reporting behavior. Figure 5 illustrates the share of groups in which specific arguments were made to encourage dishonest (Panel A) and honest reporting (Panel B) for GroupPC and GroupNoPC separately. We refer to Money if the argument made related to the monetary consequences of reporting (e.g. "we will earn more if we choose to report a higher number 
than the number shown"). Honesty arguments directly refer to honesty as a norm or value (e.g "there is no need to be honest" or "it is important to be honest"). Insecurity refers to insecurity concerning the task (e.g. "I am uncertain about the task" or "I thought we should enter the number we want to enter”). Rules refer to explicit arguments that include (non-)compliance with the rules (e.g. "we should stick to the rules" or "there is no need to stick to the rules"). Others' behavior refers to honesty of others outside the group (e.g., people’s behavior in general or other participants’ behavior).

The majority of arguments refer to Money, Honesty and Insecurity (see Figure 5). In both GroupPC and GroupNoPC, participants use Money mainly to encourage dishonest reporting, and they do so to a similar extent (Fisher's exact test, $\mathrm{p}=0.233$ ). Explicitly referring to Honesty is the main argument used in favor of honesty, being raised significantly more often in GroupNoPC (Fisher's exact test, $\mathrm{p}=0.008$ ). Insecurity is used to encourage both dishonest and honest behavior. As the use of arguments relating to Insecurity does not correlate with wrongly answered control questions in Part 2 (Spearman, referring to honesty: rho=-0.05, $\mathrm{p}=0.65$; referring to dishonesty: rho=-0.06, $\mathrm{p}=0.59$ ), participants may use these type of arguments in particular as a justification for their preferred behavior, i.e. as an excuse for dishonest behavior or as support for honest reporting.

\section{Figure 5: Arguments to encourage (dis)honest reporting} Arguments used to encourage...

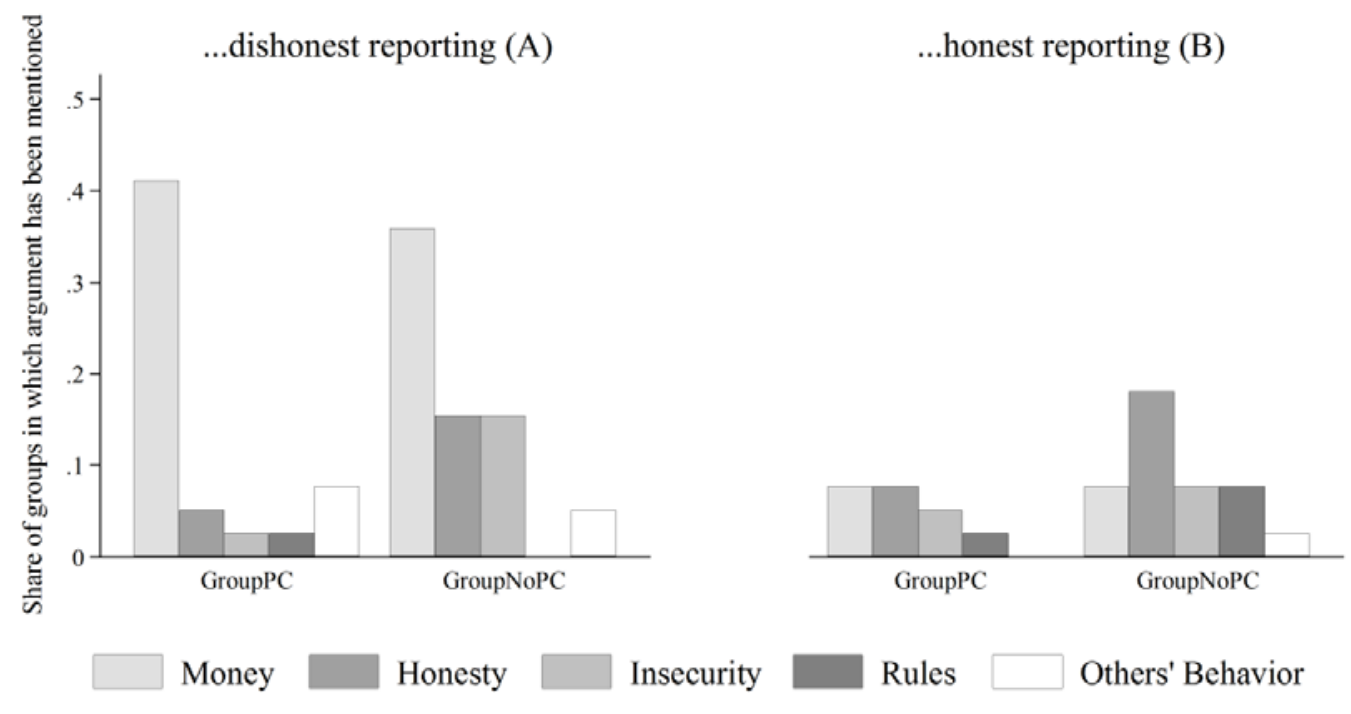


Table 3: Lying behavior and arguments used

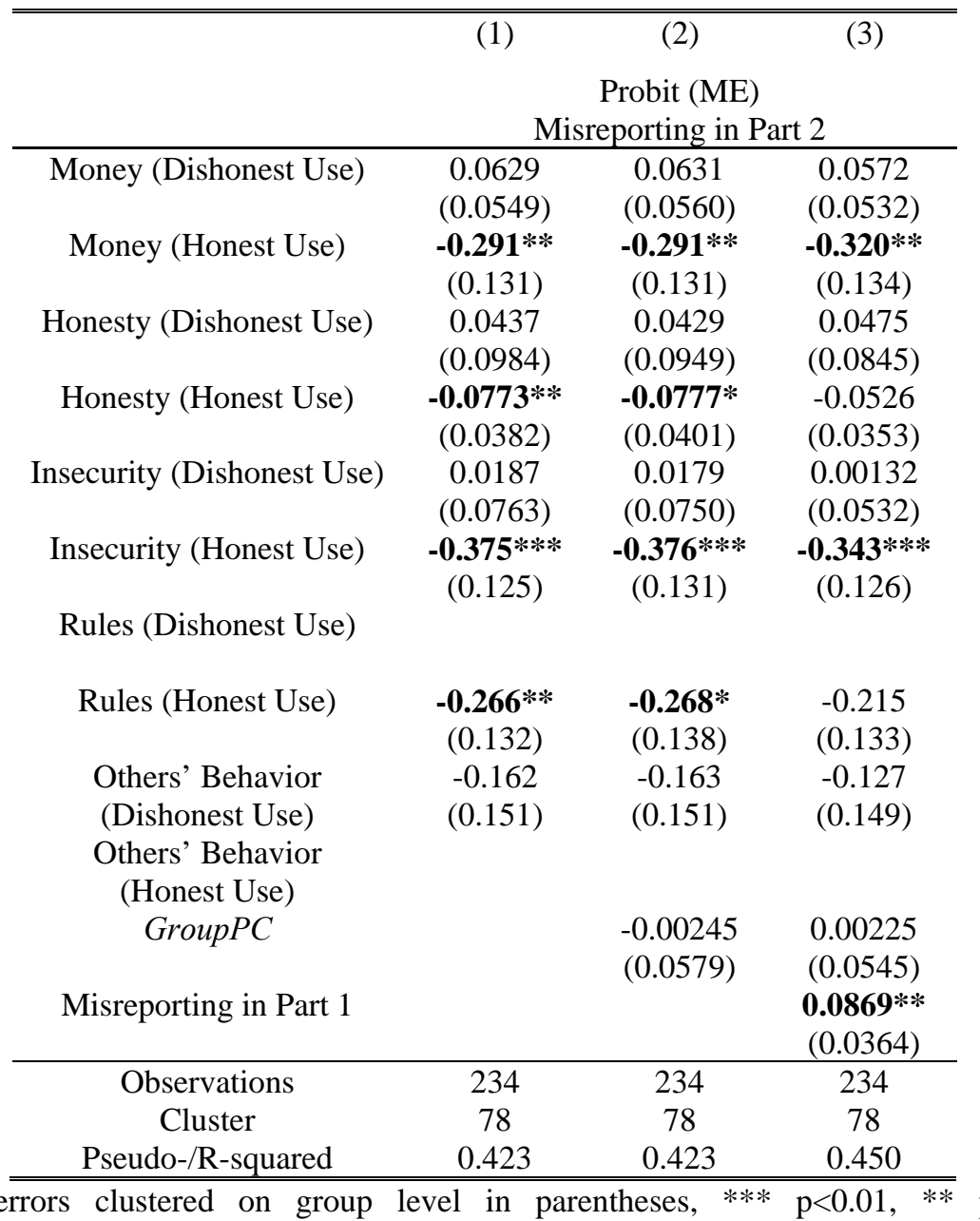

Robust standard errors clustered on group level in parentheses, ${ }^{* * *} \mathrm{p}<0.01,{ }^{* *} \mathrm{p}<0.05,{ }^{*} \mathrm{p}<0.1$. Note: Arguments relating to others' being honest and arguments referring to Rules to encourage dishonest reporting have been dropped due to multicollinearity.

Models (1) - (3) in Table 3 regress the probability of a dishonest report on arguments used for encouraging both honest and dishonest behavior. Model (1) shows that, given the high lying rates we observe, arguments that encourage honest reporting explain variation in lying best. We find that arguments in favor of honest reporting that refer to Money, Honesty, Insecurity, and Rules reduce the probability of dishonest reporting significantly. In Model (2), we introduce the treatment dummy GroupPC, which does not significantly influence dishonest reporting (compared to GroupNoPC). In Model (3) we additionally include whether or not an individual has misreported in Part 1. Misreporting in Part 1 significantly increases the probability of reporting dishonestly in Part 2. Introducing this additional control does not strongly affect the magnitude of the other coefficients 
much. However, the coefficient for Honesty (Honest Use) and Rules (Honest Use) becomes statistically insignificant in Model (3) ${ }^{20}$ We summarize these findings in Result 6.

Result 6: Arguments encouraging honesty significantly reduce lying behavior.

\subsection{Individual Characteristics and Lying}

In addition to our treatment effects, individual characteristics may play an important role for the decision to report dishonestly. As a robustness test we report results from a series of probit regressions on dishonest reporting including additional controls for individual characteristics (e.g. Machiavelli Scores, Big 5, Risk attitudes, Religiousness, Political attitudes, Gender, Age) in Tables A1-A3 of the online appendix (Section A). Our treatment effects remain robust and we find no significant effect of any control variable except for gender. ${ }^{21}$ The gender effect that we observe is in line with most previous studies: females tend to be less likely to lie as individuals (see e.g. the survey by Rosenbaum et al., 2014). Regression model (1) in Table 4 shows that females tend to misreport less in Part 2. The gender effect persists when controlling for our treatments in Model (2).

Table 4: Lying and gender

\begin{tabular}{lcccc}
\hline \hline & & \multicolumn{2}{c}{ Probit (ME) - Misreporting in Part 2 } & \\
& All & All & Females & Males \\
& $(1)$ & $(2)$ & $(3)$ & $(4)$ \\
\hline GroupPC & & $\mathbf{0 . 2 0 5 * * *}$ & $\mathbf{0 . 2 6 6 * * *}$ & 0.116 \\
& & $(0.0585)$ & $(0.0781)$ & $(0.0744)$ \\
GroupNoPC & & $\mathbf{0 . 1 6 9 * * *}$ & $\mathbf{0 . 2 3 1 * * *}$ & 0.0763 \\
& & $(0.0576)$ & $(0.0770)$ & $(0.0745)$ \\
Female & $\mathbf{- . 0 8 7 8 ^ { * * }}$ & $\mathbf{- 0 . 0 8 2 4 * *}$ & & \\
& $(0.0381)$ & $(0.0366)$ & & 106 \\
\hline Observations & 273 & 273 & 167 & 76 \\
Clustered SE & 117 & 117 & 100 & 0.031 \\
Pseudo-R2 & 0.017 & 0.079 & 0.0829 & \\
\hline \hline
\end{tabular}

Robust standard errors clustered on group level in parentheses $* * * \mathrm{p}<0.01, * * \mathrm{p}<0.05, * \mathrm{p}<0.1$

${ }^{20}$ Adding the number seen in Part 2 as an explanatory variable (proxy for the monetary gain from a lie) in Models (1) to (3) leaves the results qualitatively unchanged.

${ }^{21}$ Note that other controls do not systematically affect lying behavior in Part 1. 
However, the treatment effect on females is larger than on males (see Model (3) and (4), showing separate regressions for females and males). The coefficient for males is still positive but not statistically significant at conventional levels ( $\mathrm{p}=0.140$ for GroupPC and $\mathrm{p}=0.314$ for GroupNoPC).

\section{$4 \quad$ Discussion and Alternative Explanations}

Our results document that communication in groups can have a detrimental effect on honest reporting behavior. One rationale for this result is that communicating in a group provides possibilities for individuals to deliberate and formulate justifications for dishonest behavior (see also Gino and Ariely, 2012; Mazar et al., 2008; Shalvi et al., 2012). Another rationale is that exchanging justifications enables group members to coordinate and establish the validity of a norm regarding honesty and to what extent it is shared among others. In order to address these two aspects, we conduct an additional control treatment which allows for deliberation but not for communication; IndividualDeliberation $(\mathrm{n}=39)$. Part 1 and 3 of IndividualDeliberation are identical to the Individual treatment described in Section 2. In Part 2, IndividualDeliberation offers participants the possibility to deliberate before entering the number seen in Part 2: After observing the die roll, participants have five minutes to write down their thoughts and only afterwards enter their number. As in the group treatments (where participants could leave the chat) participants in IndividualDeliberation were allowed to leave the entry screen before its automated ending. Thus IndividualDeliberation allows participants to deliberate and formulate justifications for dishonest behavior but excludes establishing the validity arguments and sharing of the norm among group members.

Figure 6 illustrates the fraction of liars in Part 2 which is significantly smaller in both individual treatments as compared to the group treatments (Fisher's exact test, $\mathrm{p}=0.026$ for both IndividualDeliberation vs. GroupPC and IndividualDeliberation vs. GroupNoPC; $\mathrm{p}=0.007$ for both Individual vs. GroupPC and Individual vs. GroupNoPC; $\mathrm{p}=0.814$ for Individual vs. IndividualDeliberation). That is, lying with deliberation is not significantly different from lying in 


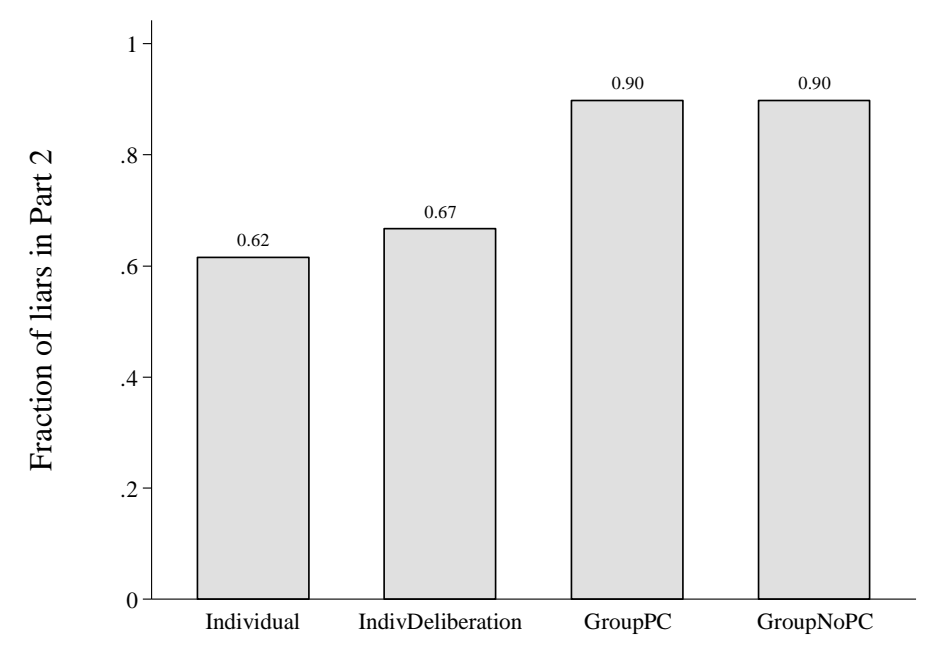

Figure 6: Lying in Part 2, by treatment.

Individual but does significantly differ from lying behavior in groups. ${ }^{22}$ Also (and again in contrast to group communication) deliberation does not significantly change the skewness of beliefs about other participants' honesty in the reference experiment (Wilcoxon signed-rank exact test, $\mathrm{p}=0.164$ ). One may expect individuals in IndividualDeliberation deliberate less than individuals in the group treatments. However, the number of individuals in IndividualDeliberation coming up with at least one dishonest argument is not statistically different from the number of groups who do so in GroupPC $\left(\chi^{2}\right.$-test, $\left.\mathrm{p}=0.352\right)$, and it is even larger than the number of groups in GroupPC $\left(\chi^{2}\right.$-test, $\left.\mathrm{p}=0.068\right){ }^{23}$ Hence, we are confident that deliberation alone does not explain the increase of lying behavior in groups. In combination with Result 1 we conclude that it is the exchange of arguments and moral views within the group that shift group members' expectations and behavior. ${ }^{24}$

Finally, let us briefly discuss other potential explanations for the observed dishonesty shift. First, one may suspect that experimenter demand effects could play a role in our setting. For instance, groups might be more susceptible to experimenter demand effects than individuals and thereby lie more (or less). Identifying such demand effects is usually difficult, and there is no existing evidence

\footnotetext{
${ }^{22}$ Note that levels of lying in Part 1 and Part 3 in IndividualDeliberation (48.7 and 76.9 percent) do not significantly differ from levels of lying in Individual (30.8 and 71.8 percent, Fisher's exact test, Part 1: p=0.165 and Part 3: $\mathrm{p}=0.796$ ).

${ }^{23}$ This also holds true for the absolute number of dishonest arguments. Online appendix (section B3) provides further results from the content analysis of IndividualDeliberation.

${ }^{24}$ This conclusion is further supported by decision times which we analyze in the online appendix (section B2).
} 
for a difference in susceptibility between individuals and groups. As we are able to observe communication of our participants we analyzed group chats with regard to any signs of experimenter demand effects. We find that only 4 out of 78 groups (5 percent) mention that the "honesty - money trade-off" might be part of the research question, and one group considered that the experimenter may be interested in the effect of the group chat on the decision. Also in IndividualDeliberation, only 5 percent (two participants) refer to the research question. Hence, we find little (direct) evidence for an experimenter demand effect that interacts with our group treatments. Such a demand effect is thus unlikely to explain the observed dishonesty shift.

Second, we observe increasing lying rates in the Individual treatment over the three parts. One may suspect that subjects learn over time that consequences of dishonest behavior are absent. If so, there is the possibility that communication in groups facilitates this "learning" and thereby increases lying rates faster. However, three empirical facts cast doubt on this interpretation. First, 74 percent of our groups do not address the potential consequences (positive or negative) of dishonest behavior, and the discussion of potential consequences does not significantly correlate with the decision to lie (Spearman's Rho: positive consequences $-0.069, \mathrm{p}=0.550$; negative consequences $-0.129, \mathrm{p}=0.260$ ). Second, we do not find a statistically significant correlation between wrongly answered control question and lying behavior. Third, faster learning in the group treatments in Part 2 is unable to explain the significant increase in beliefs about others' dishonesty in a reference experiment that we observe only for participants who communicated in a group. While participants in Individual have also learned about the consequences of lying, they do not change their beliefs about others' lying behavior much. Thus, we are confident that group communication indeed changes how people rationalize morally questionable behavior, i.e. it is learning about the norm, not about the consequences of lying.

Third, "hiding behind the group” as an individual (accountability argument) is a potential explanation for the dishonesty shift. However, this argument is hard to sustain in an environment with perfect observability by the experimenter, which we implemented on purpose to address this aspect. Further, if hiding behind the group was a main driver, lying in the Group treatments should decrease significantly in Part 3 (which we do not observe). 


\section{Conclusion}

Our results substantially improve the understanding of (dis)honest behavior in groups. First, complementing recent evidence on the role of collaboration opportunities for dishonesty when communication is absent (see Weisel and Shalvi, 2015), we observe that groups lie significantly more than individuals when group members face payoff commonality and have to coordinate on an action. Second, we show that the payoff commonality is not a necessary condition for groups to behave more dishonestly than individuals. If individuals communicate within a group but do not have to coordinate to receive a payoff, their behavior is very similar to the behavior of groups facing payoff commonality. Hence, we provide evidence that communication itself can have a detrimental effect on ethical behavior of small groups. We term this increased inclination to lie dishonesty shift. Evidence from our additional control treatment (IndividualDeliberation) shows that the dishonesty shift is not due to the fact that communicating in a group provides possibilities for individuals to deliberate or simply justify their actions to themselves. Instead, it is the exchange of justifications that enables group members to coordinate on dishonest actions and change their beliefs about moral behavior. The content analysis of our chat protocols backs up this interpretation, as it documents that group members indeed use the chat primarily to formulate and exchange arguments in favor of dishonest behavior. Additionally, we find that communication shifts group members' beliefs about the prevailing honesty norm in a reference experiment, suggesting that group members indeed established a new norm regarding (dis-)honesty.

Our findings also provide important insights for the design of institutions. We document a new argument for the prevalence of dishonesty in groups: Groups tend to lie more because they are able to communicate and thereby to rationalize morally wrong behavior in a different way than individuals. In turn, organizations fostering interaction and communication within groups are likely to provide room for group members not only to coordinate their actions, but also to adjust their beliefs and thus the norms they follow. Consequently, members of a group or unit within an organization may hold different beliefs about ethically acceptable behavior than individuals outside the group. While communication is obviously important and necessary to provide efficient coordination which can be 
beneficial in many organizational contexts it may also have detrimental effects on the evolution of norm perception within groups. Therefore, organizational structures that foster communication might require to be paired with strong codes of conduct or exogenous monitoring (and punishment) to avoid honesty norms to erode. While reminders appealing to morality or religious beliefs have been shown to be effective in the short run (Mazar et al., 2008), long run impacts of such interventions are less well understood. More research is also needed to investigate how scrutiny (see e.g. Baeker and Mechtel, 2015; Houser et al., 2016; Van de Ven and Villeval, 2015) and efficient reporting mechanisms can be designed (Friesen and Gangadharan, 2013). Our results hint at the fact that such designs need to take into account how dishonest behavior evolves in groups and raises many interesting questions for future research, e.g. on the role of hierarchies in organizations, heterogeneity in the benefits from lying, monitoring and punishment, and self-selection of honest and dishonest individuals in leading roles.

Over and above the analysis of potential organizational design features that are able to countervail the dishonesty shift, our results highlight a more general fact: communication in groups and organizations changes group members' beliefs about moral behavior of others and increases coordination of group members' behavior. While we observe a strong shift towards violating the honesty norm in groups, it remains an open question whether group members may coordinate on moral actions, depending on the original strength of the norm.

\section{References}

Abeler, J., Becker, A., Falk, A., 2014. Representative evidence on lying costs. Journal of Public Economics, 113, 96-104.

Baeker, A., Mechtel, M., 2015. Peer settings induce cheating on task performance, IAAEU Discussion Paper Series in Economics.

Bénabou, R., 2013. Groupthink: Collective delusions in organizations and markets. The Review of Economic Studies, 80, 429-462.

Bénabou, R., Tirole, J., 2006. Incentives and Prosocial Behavior. The American Economic Review, 96, 1652-1678.

Bénabou, R., Tirole, J., 2012. Laws and Norms. Working Paper.

Cappelen, A.W., Sørensen, E.Ø., Tungodden, B., 2013. When do we lie? Journal of Economic Behavior \& Organization, 93, 258-265.

Chytilova, J., Korbel, V., 2014. Individual and Group Cheating Behavior: A Field Experiment with Adolescents, Charles University Prague, Faculty of Social Sciences, Institute of Economic Studies. 
Conrads, J., Irlenbusch, B., Rilke, R.M., Walkowitz, G., 2013. Lying and team incentives. Journal of Economic Psychology, 34, 1-7.

Erat, S., Gneezy, U., 2012. White lies. Management Science, 58, 723-733.

Falk, A., Ichino, A., 2006. Clean evidence on peer effects. Journal of Labor Economics, 24, 38-57.

Falk, A., Tirole, J., 2016. Narratives, Imperatives and Moral Reasoning. Working Paper.

Fischbacher, U., 2007. z-Tree: Zurich toolbox for ready-made economic experiments. Experimental Economics, 10, 171-178.

Fischbacher, U., Föllmi-Heusi, F., 2013. Lies in disguise-an experimental study on cheating. Journal of the European Economic Association, 11, 525-547.

Friesen, L., Gangadharan, L., 2013. Designing self-reporting regimes to encourage truth telling: An experimental study. Journal of Economic Behavior \& Organization, 94, 90-102.

Gino, F., Ariely, D., 2012. The dark side of creativity: original thinkers can be more dishonest. Journal of Personality and Social Psychology, 102, 445-459.

Gino, F., Ayal, S., Ariely, D., 2013. Self-serving altruism? The lure of unethical actions that benefit others. Journal of Economic Behavior \& Organization, 93, 285-292.

Glätzle-Rützler, D., Lergetporer, P., 2015. Lying and age: An experimental study. Journal of Economic Psychology, 46, 12-25.

Gneezy, U., 2005. Deception: The role of consequences. American Economic Review, 95, 384-394.

Gneezy, U., Rockenbach, B., Serra-Garcia, M., 2013. Measuring lying aversion. Journal of Economic Behavior \& Organization, 93, 293-300.

Greiner, B., 2015. Subject pool recruitment procedures: organizing experiments with ORSEE. Journal of the Economic Science Association, 1, 114-125.

Houser, D., List, J.A., Piovesan, M., Samek, A., Winter, J., 2016. Dishonesty: From parents to children. European Economic Review, 82, 242-254.

Kajackaite, A., Gneezy, U., 2015. Lying Costs and Incentives. Working Paper.

Kocher, M., Strauß, S., Sutter, M., 2006. Individual or team decision-making-causes and consequences of self-selection. Games and Economic Behavior, 56, 259-270.

Kocher, M.G., Sutter, M., 2005. The Decision Maker Matters: Individual Versus Group Behaviour in Experimental Beauty-Contest Games. The Economic Journal, 115, 200-223.

Kröll, M., Rustagi, D., 2016. Got milk? Motivation for honesty and cheating in informal markets: Evidence from India, Research Center SAFE-Sustainable Architecture for Finance in Europe, Goethe University Frankfurt.

Lundquist, T., Ellingsen, T., Gribbe, E., Johannesson, M., 2009. The aversion to lying. Journal of Economic Behavior and Organization, 70, 81-92.

Mazar, N., Amir, O., Ariely, D., 2008. The dishonesty of honest people: A theory of self-concept maintenance. Journal of Marketing Research, 45, 633-644.

Muehlheusser, G., Roider, A., Wallmeier, N., 2015. Gender differences in honesty: Groups versus individuals. Economics Letters, 128, 25-29.

Pruitt, D.G., Teger, A.I., 1969. The risky shift in group betting. Journal of Experimental Social Psychology, 5, 115-126.

Rosenbaum, S.M., Billinger, S., Stieglitz, N., 2014. Let's be honest: A review of experimental evidence of honesty and truth-telling. Journal of Economic Psychology, 45, 181-196.

Shalvi, S., Eldar, O., Bereby-Meyer, Y., 2012. Honesty requires time (and lack of justifications). Psychological Science, 23, 1264-1270.

Sutter, M., 2009. Deception through telling the truth?! experimental evidence from individuals and teams. The Economic Journal, 119, 47-60.

Teger, A.I., Pruitt, D.G., 1967. Components of group risk taking. Journal of Experimental Social Psychology, 3, 189-205.

Van de Ven, J., Villeval, M.C., 2015. Dishonesty under scrutiny. Journal of the Economic Science Association, 1, 86-99.

Weisel, O., Shalvi, S., 2015. The collaborative roots of corruption. Proceedings of the National Academy of Sciences, 112, 10651-10656.

Wiltermuth, S.S., 2011. Cheating more when the spoils are split. Organizational Behavior and Human Decision Processes, 115, 157-168. 


\section{Online Appendix}

\section{A - Additional robustness tests}

Table A1: Lying and social preferences

\begin{tabular}{|c|c|c|c|c|c|c|c|c|c|}
\hline & \multicolumn{9}{|c|}{$\begin{array}{c}\text { Probit (ME) } \\
\text { Misreporting in Part } 2 \\
\end{array}$} \\
\hline GroupPC & $\begin{array}{c}\mathbf{0 . 2 0 9} * * * \\
(0.0591)\end{array}$ & $\begin{array}{c}\mathbf{0 . 2 0 9} * * * \\
(0.0595)\end{array}$ & $\begin{array}{c}\mathbf{0 . 2 0 7 * * *} \\
(0.0592)\end{array}$ & $\begin{array}{c}\mathbf{0 . 2 0 9} * * * \\
(0.0595)\end{array}$ & $\begin{array}{c}\mathbf{0 . 2 0 9} * * * \\
(0.0584)\end{array}$ & $\begin{array}{c}\mathbf{0 . 2 0 8} * * * \\
(0.0606)\end{array}$ & $\begin{array}{c}\mathbf{0 . 2 0 8} * * * \\
(0.0595)\end{array}$ & $\begin{array}{c}\mathbf{0 . 2 0 5} * * * \\
(0.0590)\end{array}$ & $\begin{array}{c}\mathbf{0 . 2 0 6} * * * \\
(0.0577)\end{array}$ \\
\hline GroupNoPC & $\begin{array}{l}\text { 0.170*** } \\
(0.0584)\end{array}$ & $\begin{array}{l}\text { 0.173*** } \\
(0.0585)\end{array}$ & $\begin{array}{c}\mathbf{0 . 1 7 3} * * * \\
(0.0585)\end{array}$ & $\begin{array}{c}\mathbf{0 . 1 7 4 * * *} \\
(0.0586)\end{array}$ & $\begin{array}{c}\mathbf{0 . 1 7 4} * * * \\
(0.0593)\end{array}$ & $\begin{array}{c}\text { 0.173*** } \\
(0.0575)\end{array}$ & $\begin{array}{c}\mathbf{0 . 1 7 3} * * * \\
(0.0586)\end{array}$ & $\begin{array}{c}\mathbf{0 . 1 6 7 * * *} \\
(0.0583)\end{array}$ & $\begin{array}{c}\mathbf{0 . 1 6 3} * * * \\
(0.0561)\end{array}$ \\
\hline Machiavelli (self) & $\begin{array}{c}0.00350 \\
(0.00327)\end{array}$ & & & & & & & & $\begin{array}{c}0.00156 \\
(0.00324)\end{array}$ \\
\hline Machiavelli (other) & & $\begin{array}{c}0.00163 \\
(0.00316)\end{array}$ & & & & & & & $\begin{array}{c}0.00157 \\
(0.00256)\end{array}$ \\
\hline Conscientiousness & & & $\begin{array}{l}-0.00713 \\
(0.0113)\end{array}$ & & & & & & $\begin{array}{l}0.00282 \\
(0.0121)\end{array}$ \\
\hline Neuroticism & & & & $\begin{array}{l}0.00214 \\
(0.0121)\end{array}$ & & & & & $\begin{array}{c}0.000840 \\
(0.0123)\end{array}$ \\
\hline Openness & & & & & $\begin{array}{l}-\mathbf{- 0 . 0 2 0 6 *} \\
(0.0109)\end{array}$ & & & & $\begin{array}{l}-\mathbf{0 . 0 1 9 9} * \\
(0.0113)\end{array}$ \\
\hline Extraversion & & & & & & $\begin{array}{c}-0.000513 \\
(0.0105)\end{array}$ & & & $\begin{array}{l}0.00132 \\
(0.0120)\end{array}$ \\
\hline Agreeableness & & & & & & & $\begin{array}{l}0.00391 \\
(0.0119)\end{array}$ & & $\begin{array}{c}0.0171 \\
(0.0146)\end{array}$ \\
\hline Social Desirability & & & & & & & & $\begin{array}{c}0.0202 \\
(0.0147)\end{array}$ & $\begin{array}{c}0.0188 \\
(0.0166)\end{array}$ \\
\hline Observations & 273 & 273 & 273 & 273 & 273 & 273 & 273 & 273 & 273 \\
\hline \# cluster & 117 & 117 & 117 & 117 & 117 & 117 & 117 & 117 & 117 \\
\hline Pseudo-R & 0.070 & 0.065 & 0.064 & 0.064 & 0.078 & 0.063 & 0.064 & 0.076 & 0.095 \\
\hline
\end{tabular}

Robust standard errors clustered on group level in parentheses ${ }^{* * *} \mathrm{p}<0.01,{ }^{* *} \mathrm{p}<0.05, * \mathrm{p}<0.1$ 
Table A2: Lying and risk preferences

\begin{tabular}{|c|c|c|c|c|c|c|}
\hline & (1) & (2) & $\begin{array}{r}\text { Pro } \\
\text { Pro } \\
\text { Misrepo } \\
\end{array}$ & \begin{tabular}{l}
\multicolumn{1}{|c}{$(4)$} \\
ME) \\
in Part 2 \\
\end{tabular} & (5) & (6) \\
\hline GroupPC & $\begin{array}{c}\mathbf{0 . 2 0 8} * * * \\
(0.0598)\end{array}$ & $\begin{array}{c}\mathbf{0 . 2 1 3} * * * \\
(0.0600)\end{array}$ & $\begin{array}{c}\mathbf{0 . 2 1 0} * * * \\
(0.0590)\end{array}$ & $\begin{array}{c}\mathbf{0 . 2 0 8}^{* * *} \\
(0.0596)\end{array}$ & $\begin{array}{c}\mathbf{0 . 2 0 5} * * * \\
(0.0616)\end{array}$ & $\begin{array}{c}\text { 0.211**** } \\
(0.0610)\end{array}$ \\
\hline GroupNoPC & $\begin{array}{c}\mathbf{0 . 1 7 3} * * * \\
(0.0586)\end{array}$ & $\begin{array}{c}\mathbf{0 . 1 8 0} * * * \\
(0.0583)\end{array}$ & $\begin{array}{c}\mathbf{0 . 1 7 3} * * * \\
(0.0583)\end{array}$ & $\begin{array}{c}\mathbf{0 . 1 7 3} * * * \\
(0.0585)\end{array}$ & $\begin{array}{c}\mathbf{0 . 1 7 2} * * * \\
(0.0578)\end{array}$ & $\begin{array}{c}\mathbf{0 . 1 7 7} * * * \\
(0.0564)\end{array}$ \\
\hline Risk (General) & $\begin{array}{c}-0.00483 \\
(0.0133)\end{array}$ & & & & & $\begin{array}{r}-0.00925 \\
(0.0203)\end{array}$ \\
\hline Risk (Car) & & $\begin{array}{c}0.0126 \\
(0.0145)\end{array}$ & & & & $\begin{array}{c}0.0141 \\
(0.0159)\end{array}$ \\
\hline Risk (Money) & & & $\begin{array}{c}0.00610 \\
(0.0144)\end{array}$ & & & $\begin{array}{c}0.00920 \\
(0.0177)\end{array}$ \\
\hline Risk (Sport) & & & & $\begin{array}{c}-0.000757 \\
(0.0114)\end{array}$ & & $\begin{array}{c}0.00005 \\
(0.0125)\end{array}$ \\
\hline Risk (Career) & & & & & $\begin{array}{c}-0.00743 \\
(0.0160)\end{array}$ & $\begin{array}{r}-0.00931 \\
(0.0236)\end{array}$ \\
\hline Observations & 273 & 273 & 273 & 273 & 273 & 273 \\
\hline \# of Cluster & 117 & 117 & 117 & 117 & 117 & 117 \\
\hline Pseudo - R & 0.064 & 0.067 & 0.064 & 0.063 & 0.064 & 0.071 \\
\hline
\end{tabular}

Robust standard errors clustered on group level in parentheses

$* * * \mathrm{p}<0.01,{ }^{* *} \mathrm{p}<0.05,{ }^{*} \mathrm{p}<0.1$ 
Table A3: Lying and socio-economic background

\begin{tabular}{|c|c|c|c|c|c|c|c|}
\hline & (1) & (2) & $\begin{array}{l}\text { (3) } \\
\text { Misı } \\
\end{array}$ & $\begin{array}{l}\text { (4) } \\
\text { robit (ME) } \\
\text { porting in } \mathrm{Pa}\end{array}$ & (5) & (6) & (7) \\
\hline GroupPC & $\begin{array}{c}\mathbf{0 . 2 0 5 * * *} \\
(0.0585)\end{array}$ & $\begin{array}{c}\mathbf{0 . 2 0 8 * * *} \\
(0.0594)\end{array}$ & $\begin{array}{c}\mathbf{0 . 2 0 9} * * * \\
(0.0590)\end{array}$ & $\begin{array}{c}\mathbf{0 . 2 0 8}^{* * *} \\
(0.0590)\end{array}$ & $\begin{array}{c}\mathbf{0 . 2 0 9 * * *} \\
(0.0595)\end{array}$ & $\begin{array}{c}\mathbf{0 . 2 0 4} * * * \\
(0.0594)\end{array}$ & $\begin{array}{r}\text { 0.201*** } \\
(0.0574)\end{array}$ \\
\hline GroupNoPC & $\begin{array}{c}\mathbf{0 . 1 6 9 * * *} \\
(0.0576)\end{array}$ & $\begin{array}{c}\mathbf{0 . 1 6 9 * * *} \\
(0.0584)\end{array}$ & $\begin{array}{c}\mathbf{0 . 1 7 2 * * *} \\
(0.0581)\end{array}$ & $\begin{array}{c}\mathbf{0 . 1 6 6 * * *} \\
(0.0585)\end{array}$ & $\begin{array}{c}\mathbf{0 . 1 7 3} * * * \\
(0.0588)\end{array}$ & $\begin{array}{c}\mathbf{0 . 1 6 9 * * *} \\
(0.0583)\end{array}$ & $\begin{array}{l}\mathbf{0 . 1 5 4 * *} \\
(0.0565)\end{array}$ \\
\hline Female & $\begin{array}{c}\mathbf{- 0 . 0 8 2 4 * *} \\
(0.0366)\end{array}$ & & & & & & $\begin{array}{r}\mathbf{- 0 . 0 7 1 7 * *} \\
(0.0363)\end{array}$ \\
\hline $\begin{array}{l}\text { Importance of religious questions } \\
\text { (1=not important at all, } 7=\text { very important) }\end{array}$ & & $\begin{array}{l}-0.00933 \\
(0.00890)\end{array}$ & & & & & $\begin{array}{r}-0.00662 \\
(0.0085)\end{array}$ \\
\hline $\begin{array}{l}\text { Political Attitude } \\
\text { (1=strongly left, } 7=\text { strongly right) }\end{array}$ & & & $\begin{array}{c}0.0239 \\
(0.0194)\end{array}$ & & & & $\begin{array}{c}0.0222 \\
(0.0199)\end{array}$ \\
\hline Age & & & & $\begin{array}{c}0.00523 \\
(0.00452)\end{array}$ & & & $\begin{array}{c}0.00461 \\
(0.00414)\end{array}$ \\
\hline Number of other participants known & & & & & $\begin{array}{l}-0.0285 \\
(0.0650)\end{array}$ & & $\begin{array}{l}-0.0167 \\
(0.0588)\end{array}$ \\
\hline Number experiments participated in & & & & & & $\begin{array}{l}\mathbf{0 . 0 0 5 3 9 *} \\
(0.00290)\end{array}$ & $\begin{array}{c}0.00447 \\
(0.00284)\end{array}$ \\
\hline Observations & 273 & 273 & 273 & 273 & 273 & 273 & 273 \\
\hline \# of Clusters & 117 & 117 & 117 & 117 & 117 & 117 & 117 \\
\hline Pseudo-R & 0.079 & 0.066 & 0.070 & 0.069 & 0.065 & 0.078 & 0.104 \\
\hline
\end{tabular}

Robust standard errors clustered on group level in parentheses

$$
* * * \mathrm{p}<0.01, * * \mathrm{p}<0.05, * \mathrm{p}<0.1
$$




\section{B: Additional Analyses (Group composition, decision times and IndividualDeliberation)}

\section{B1: Group Composition}

In our main analysis we have shown that for the full sample (78 groups), the number of dishonest individuals in a group plays only a weak role for lying behavior in Part 2. Here we provide an additional analysis by excluding those participants who have seen a $\bigcirc$ in Part 1 and thus had no incentive to lie in Part 1 . Focusing on this subsample (66 groups) we find some evidence for differences in misreporting across group composition. In GroupPC, the correlation between the number of honest individuals in a group and honest reporting is small and fails to be statistically significant (Rho: 0.148, $\mathrm{p}=0.41$ ) and Fisher's exact test fails to reject the independence of lying behavior from group composition at the 10-percent level ( $\mathrm{p}=1$ ). In GroupNoPC, for the subsample (33 groups) the share of dishonest individuals in Part 2 correlates significantly and positively with the number of group members who have reported dishonestly in Part 1 (Rho: 0.362, $\mathrm{p}=0.0382$ ), but Fisher's exact test again fails to reject independence of group composition and lying behavior in Part $2(\mathrm{p}=0.147)$.

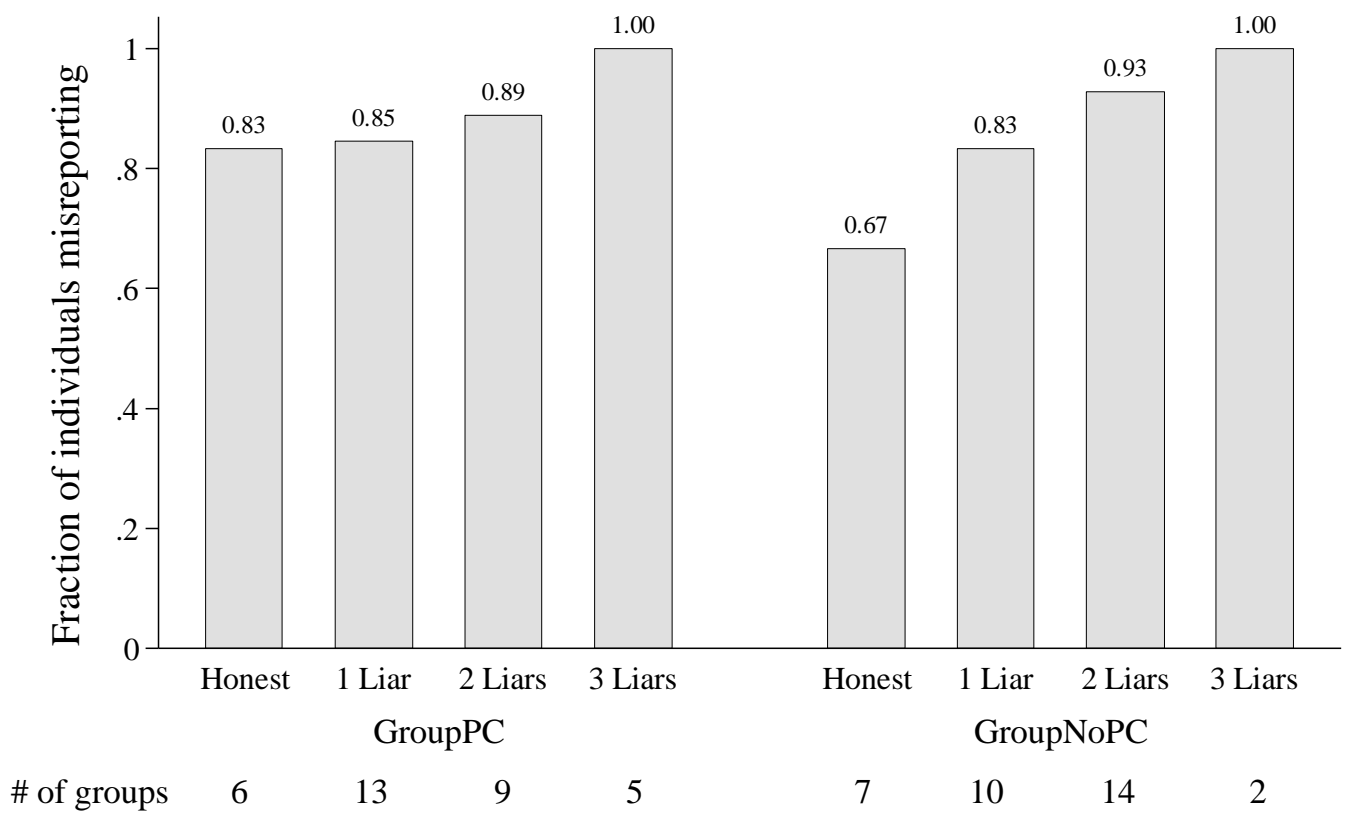

Figure B1: Dishonest reporting by group composition and treatment (subsample, 66 groups in total) 


\section{B2: Decision Times}

A recent debate surrounds the question of whether honesty or dishonesty is the "natural state" or requires deliberation (Foerster et al., 2013; Shalvi et al., 2012, 2013; Van't Veer et al., 2014). In the context of group decision making, uncertainty about the norm may result in longer decision times, whereas certainty about a prevailing (dis)honesty norm may result in shorter decision times. We find that in Part 1, misreporting individuals (on average 37 percent) take significantly longer in their decision to lie as compared to the individuals reporting the die roll that was actually displayed (mean honest reporting time: 12.64 sec (SD: 4.71); mean dishonest reporting time: 16.89 sec (SD: 9.20), Kolmogorov-Smirnov exact test, $\mathrm{p}=0.012$, Spearman's Rho: 0.296, $\mathrm{p}=0.001$ ). Having communicated in a group makes decisions in the lying task significantly faster in Part 3 (mean reporting time: Individual: 13.49 sec (SD: 6.24); mean reporting time for GroupPC and GroupNoPC pooled: 10.40 sec (SD: 3.46), Kolmogorov-Smirnov exact test, $\mathrm{p}=0.001) .{ }^{27}$ Further, in Part 3 , decision times and dishonest behavior do not significantly relate to each other (mean honest reporting time: 11.08 sec (SD: 3.79); mean dishonest reporting time: 11.52 sec (SD: 5.02), KolmogorovSmirnov exact test, $\mathrm{p}=0.857$, Spearman's Rho: 0.019, $\mathrm{p}=0.838$ ). Notably, conditional on dishonest reporting in Part 3, participants who participated in the group chat report significantly faster nontruthfully than participants from the Individual treatment (Kolmogorov-Smirnov exact 0.004; Spearman's Rho: $-0.27, \mathrm{p}=0.008$; mean reporting time with communication: 10.48 , SD: 3.71; without communication: 13.94, SD: 6.67). Having participated in the chat also speeds up decisions in the belief elicitation task (Kolmogorov-Smirnov exact test, $\mathrm{p}=0.003$ ). This might be seen as additional evidence that the chat has shifted beliefs about the honesty norm.

${ }^{27}$ As GroupPC and GroupNoPC do not differ significantly in terms of decision times in Part 3 (KolmogorovSmirnov exact test, lying decision: $\mathrm{p}=0.467$; belief elicitation time: $\mathrm{p}=0.862$ ) and to avoid multiple testing, we pool both group treatments and test them jointly against Individual. 


\section{B3: Content analysis of IndividualDeliberation}

As for the chats of the group treatments, coders analyzed the content of the stream of thoughts of IndividualDeliberation according to the pre-defined codebook in Appendix D. Our results show that many participants did indeed deliberate in this treatment. Participants took on average 234 seconds (std. dev. $=114.3$ ) to write down their thoughts and 67 percent of participants (26 out of 39) in IndividualDeliberation explicitly mention arguments for dishonesty, whereas only 9 participants write down arguments for honesty (see Table B1). Only one participant decided not to write anything. Interestingly, frequencies of dishonest and honest arguments are not statistically different than in the group treatments $\left(\chi^{2}\right.$-test, GroupPC and GroupNoPC pooled, dishonest arguments: $\mathrm{p}=0.114$; honest arguments: $\mathrm{p}=0.878$ ). The average share of statements containing arguments for dishonest behavior amounts to 59.2 percent and - as in the group treatments - is significantly higher than the share of honest messages (15.1 percent, Wilcoxon signed-rank exact test, $\mathrm{p}<0.001$ ).

Table B1: Number of individuals using honest and dishonest arguments

\begin{tabular}{cccc}
\hline \multicolumn{4}{c}{$\begin{array}{c}\text { Arguments for } \\
\text { Dishonesty mentioned }\end{array}$} \\
\hline $\begin{array}{c}\text { Arguments for } \\
\text { Honesty mentioned }\end{array}$ & Yes & No & $\sum$ \\
\hline Yes & 6 & 3 & 9 \\
No & 20 & 10 & 30 \\
$\Sigma$ & 26 & 13 & 39 \\
\hline \hline
\end{tabular}

To analyze the influence of arguments made on misreporting behavior, we replicate Table 3 from the main text including the data from IndividualDeliberation in Table B2. The results are qualitatively similar and most importantly, when including a dummy for the group treatments in Model (2), we find that groups lie significantly more, even when controlling for the arguments made during the chat. This result is robust to controlling for misreporting in Part 1 (Model (3)). The analysis of IndividualDeliberation and its comparison with our two group treatments suggests that individuals come up with dishonest and honest argument to a similar extent as groups. Yet only the exchange and validation of these arguments within a group can lead to a shift in beliefs about the norm and corresponding changes in behavior. 
Table B2: Lying behavior and arguments used

\begin{tabular}{|c|c|c|c|}
\hline & (1) & $\begin{array}{c}\text { (2) } \\
\text { Probit (ME) } \\
\text { Misreporting in } 2 \\
\end{array}$ & (3) \\
\hline Money (Dishonest Use) & $\begin{array}{c}0.0485 \\
(0.0480)\end{array}$ & $\begin{array}{c}0.0630 \\
(0.0474)\end{array}$ & $\begin{array}{c}0.0537 \\
(0.0455)\end{array}$ \\
\hline Money (Honest Use) & $\begin{array}{c}\mathbf{- 0 . 4 0 6 * * *} \\
(0.154)\end{array}$ & $\begin{array}{c}-\mathbf{0 . 4 1 6} * * * \\
(0.160)\end{array}$ & $\begin{array}{c}-\mathbf{0 . 4 4 8} * * * \\
(0.158)\end{array}$ \\
\hline Honesty (Dishonest Use) & $\begin{array}{c}-0.00915 \\
(0.111)\end{array}$ & $\begin{array}{c}-0.00619 \\
(0.0879)\end{array}$ & $\begin{array}{c}-0.0263 \\
(0.0827)\end{array}$ \\
\hline Honesty (Honest Use) & $\begin{array}{l}-0.0709 \\
(0.0475)\end{array}$ & $\begin{array}{l}-\mathbf{- 0 . 0 7 8 5 *} \\
(0.0450)\end{array}$ & $\begin{array}{l}-0.0438 \\
(0.0403)\end{array}$ \\
\hline Insecurity (Dishonest Use) & $\begin{array}{c}0.0288 \\
(0.0663)\end{array}$ & $\begin{array}{c}0.0111 \\
(0.0666)\end{array}$ & $\begin{array}{c}-0.00664 \\
(0.0533)\end{array}$ \\
\hline Insecurity (Honest Use) & $\begin{array}{c}-\mathbf{0 . 3 5 4} * * \\
(0.144)\end{array}$ & $\begin{array}{c}\mathbf{- 0 . 2 7 7 *} \\
(0.160)\end{array}$ & $\begin{array}{c}-0.209 \\
(0.155)\end{array}$ \\
\hline Rules (Dishonest Use) & & & \\
\hline Rules (Honest Use) & $\begin{array}{c}\mathbf{- 0 . 3 0 8 *} \\
(0.173)\end{array}$ & $\begin{array}{c}-\mathbf{0 . 3 1 6} * * \\
(0.155)\end{array}$ & $\begin{array}{c}-\mathbf{0 . 2 4 9} * \\
(0.144)\end{array}$ \\
\hline Others' Behavior (Dishonest Use) & $\begin{array}{c}-0.0468 \\
(0.109)\end{array}$ & $\begin{array}{l}0.0839 \\
(0.104)\end{array}$ & $\begin{array}{c}0.0926 \\
(0.104)\end{array}$ \\
\hline Others' Behavior (Honest Use) & & & \\
\hline Group Treatments (Dummy) & & $\begin{array}{c}\text { 0.330*** } \\
(0.103)\end{array}$ & $\begin{array}{c}\mathbf{0 . 3 5 1} * * * \\
(0.107)\end{array}$ \\
\hline Misreporting in Part 1 & & & $\begin{array}{c}\mathbf{0 . 1 2 0} * * * \\
(0.0370)\end{array}$ \\
\hline Observations & 273 & 273 & 273 \\
\hline Clusters & 117 & 117 & 117 \\
\hline Pseudo-R-squared & 0.280 & 0.358 & 0.396 \\
\hline
\end{tabular}




\section{C - Translated Instructions}

Appendix C includes the translated instructions (from German). Participants received the general instructions for the experiment in print. All further instructions were displayed on the computer screen at the beginning of the respective parts (see screenshots). We added comments in squared brackets [].

\section{General Instructions [printed]}

\section{Welcome to the experiment and thank you for your participation!}

Please do not speak from now on with any other participant

\section{General procedures}

In this experiment we study economic decision making. You can earn money by participating. The money you earn will be paid to you after the experiment privately and in cash.

The experiment consists of three parts in which you will take independent decisions. At the beginning of each part you will receive detailed instructions. If you have any questions about the instructions or during the experiment, please raise your hand. An instructor will then come to you and answer your questions privately.

During the experiment, you and the other participants will make decisions and possibly you may interact with other participants. That is, both your own decisions and the decisions of the other participants may determine your payoff. How your payoff is exactly determined will be explained in the on-screen instructions.

\section{Payment}

In some parts of the experiment, we are not talking about Euro but about points. Your income for these parts is calculated in points. We will convert the points into euros at the end of the experiment, with an exchange rate of:

$$
1 \text { point }=2 \text { Euro }
$$

We will randomly select one of the three parts to be payoff relevant at the end of the experiment. Participant at seat 21 will roll a die. If the die shows a $\odot$ or $\odot$, the first part of the experiment will be payoff relevant. If the die shows a $\odot$ or $\odot$, the second part is payoff relevant and if the die shows a $\odot$ or i: the third part will be payoff relevant. As all parts are equally likely to be payoff relevant it is optimal for you to decide according to your preferences.

In addition to the income that you earn during the experiment you will receive 4 euros for showing up on time. Your total income will be paid to you after the end of the experiment in cash. We will call each participant based on her seat number for individual payment. That is, no other participant will learn your payoff and also you will not learn the other participants’ payoffs.

\section{Anonymity}

The analysis of the experiment will be anonymous. That is, we will never link your name with the data generated in the experiment. You will not learn the identity of any other participant, neither before nor after the experiment. Also the other participants will not learn your identity. At the end of the experiment, you have to sign a receipt to confirm the payments you received. This receipt will only be used for accounting purposes. 
On screen instructions: Instructions for Part 1

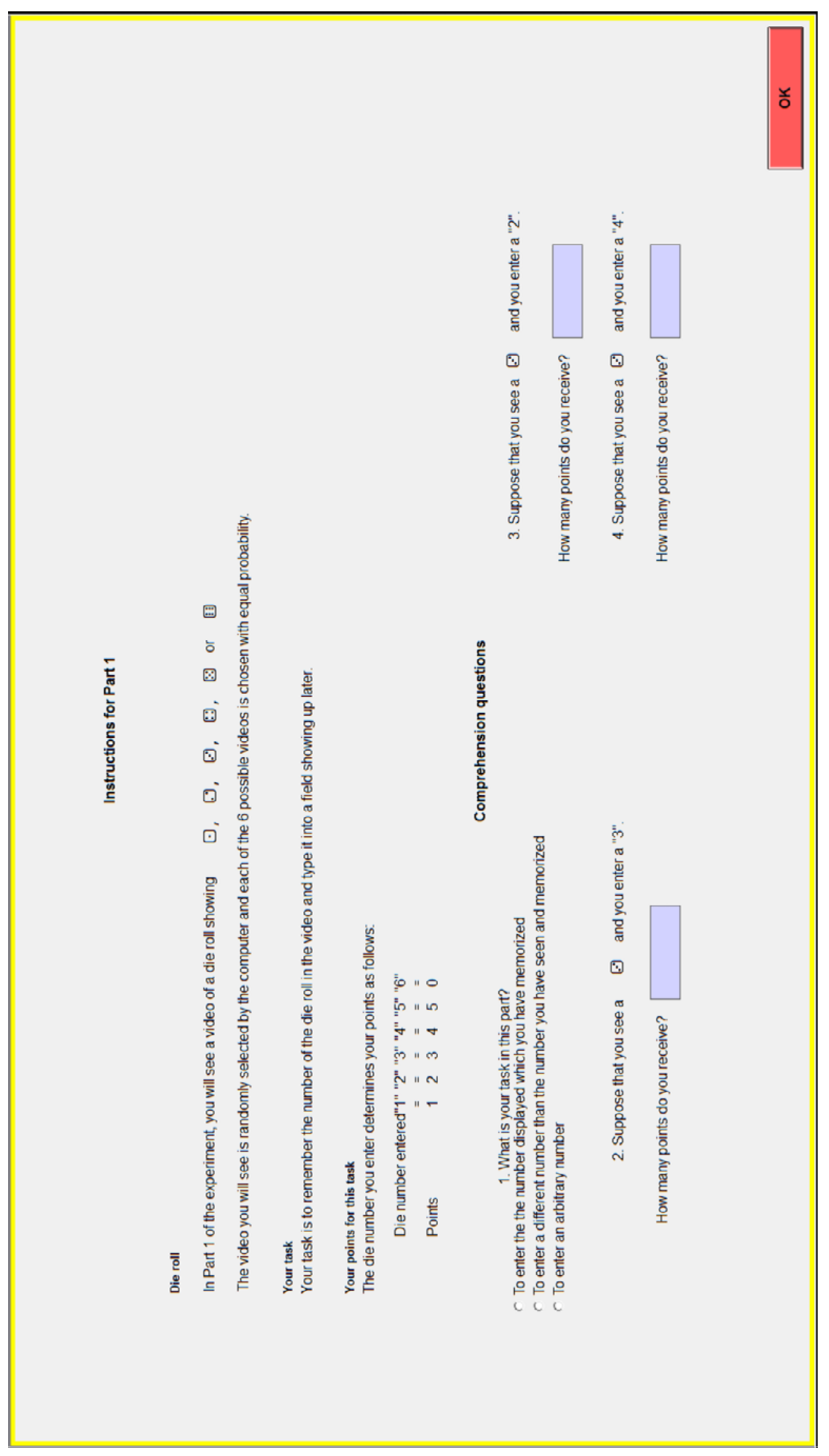


Decision Screen Part 1 [displayed after subjects observed the video]

Now enter the number from the die roll in the video.

Number seen:

The die number you enter determines the number of your points as follows:

Number entered:

"1"

"2"

"3"

" 4 "

"5"

"6"

Points

$=$

$=$

$=$

0

Belief elicitation after Part 1 [displayed after subjects entered their decision]

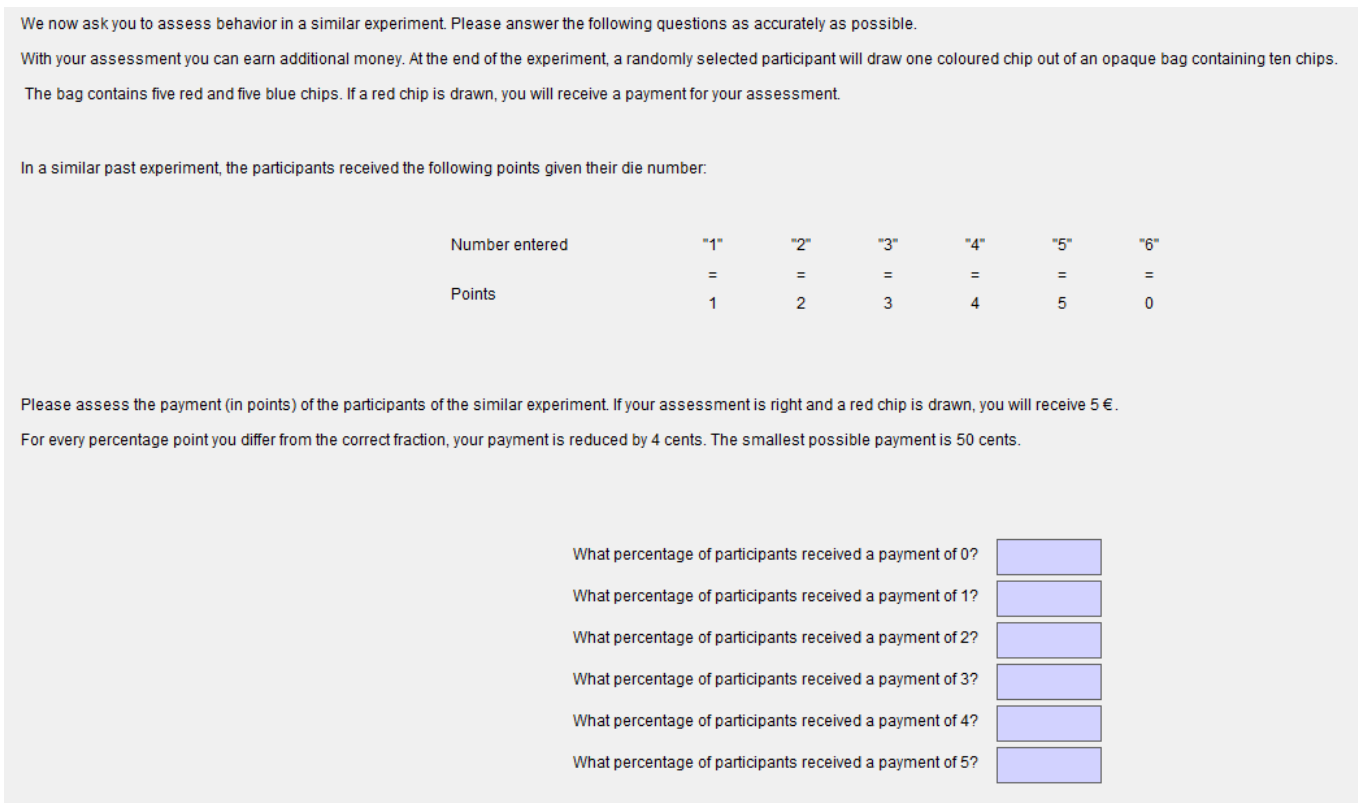

Post belief elicitation question [displayed on single screen after belief elicitation]

How sure are you about your assessment?

very unsure $\mathrm{C} C \mathrm{C} C$ very sure 


\section{Instruction for Part 2: GroupNoPC}

[for GroupPC, instructions were identical except for the fact that participants were informed that all group members receive a payoff of 0 , if they do not enter the same number, for Individual, the instructions were identical to Part 1 with an additional sentence explaining that Part 2 is identical to Part 1.]

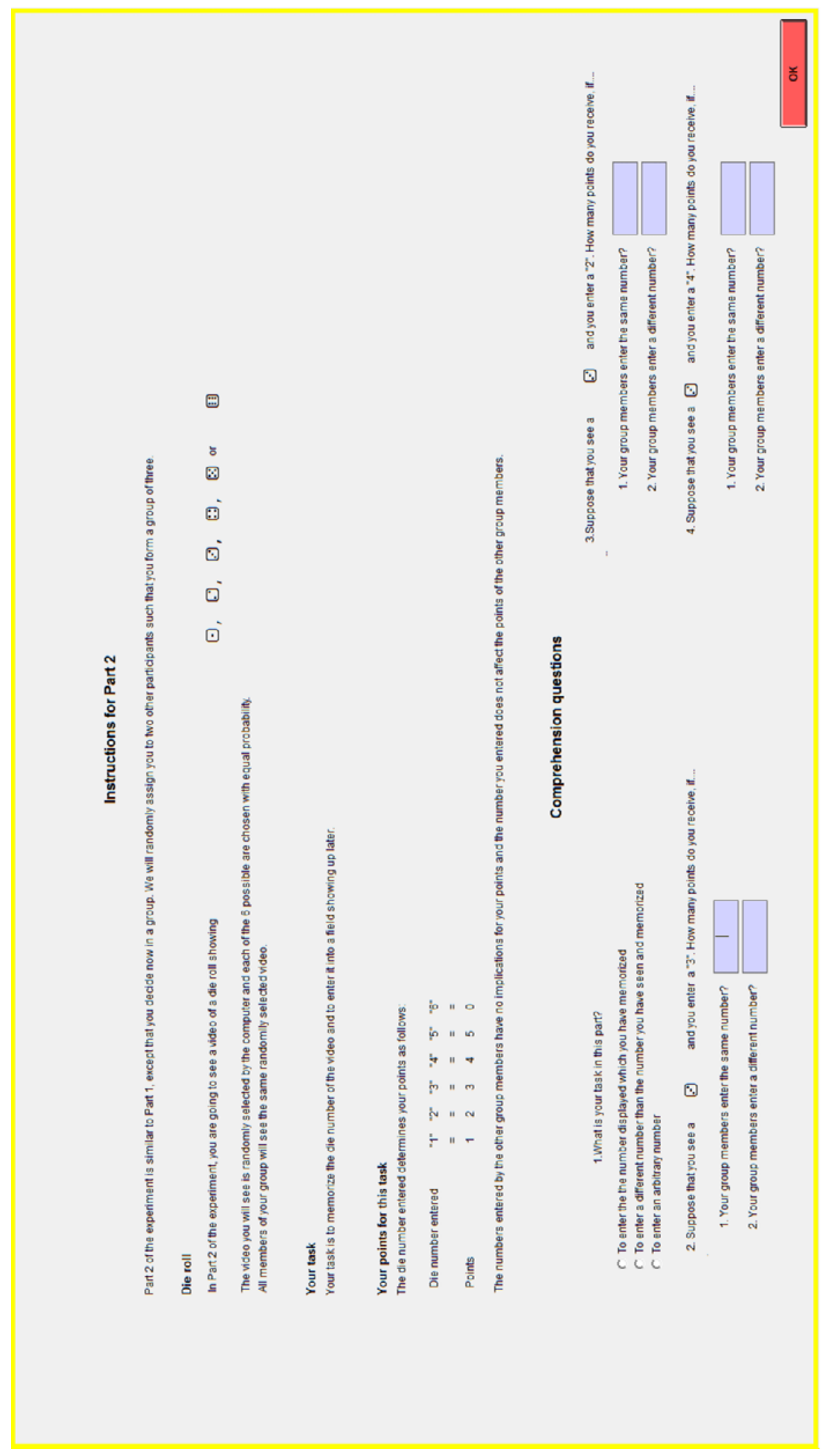


Instruction for chat [displayed after instructions for Part 2]

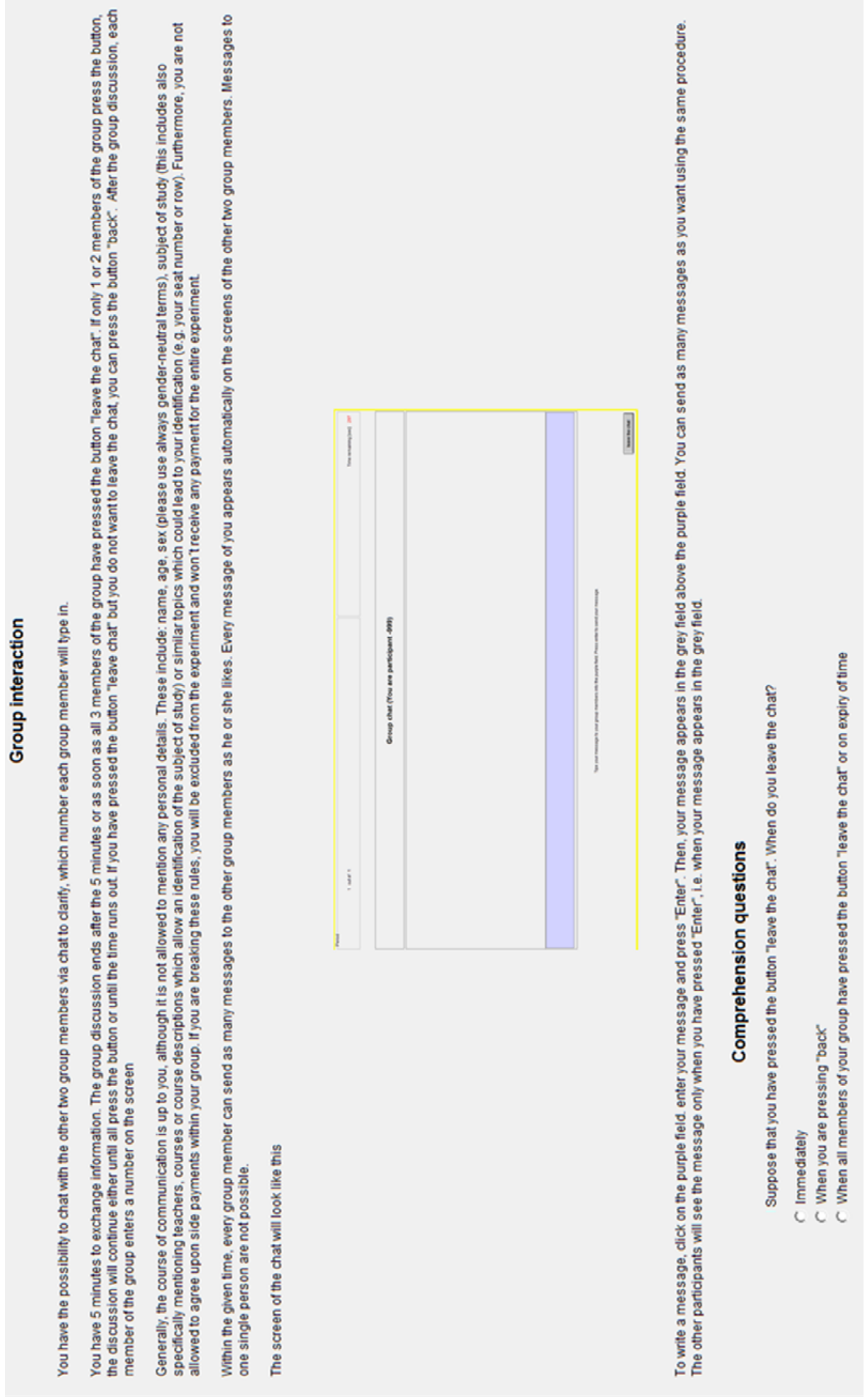




\section{Decision Screen in Part 2 and 3}

[Decision screens in Part 2 and Part 3 were structured as in Part 1.]

\section{Instructions for Part 3 and Belief elicitation after Part 3}

[Instructions for Part 3 were identical to instructions for Part 1 except that answers to control questions were automatically selected and displayed. The belief elicitation for after Part 3 was identical to the belief elicitation after Part 1, except for the color of the chip determining payoff relevance, and it was explicitly mentioned that we are asking for the expected results for the same reference experiment.]

\section{Instructions for the additional control treatment IndividualDeliberation}

[Instructions and decision screens for Part 1 and Part 3 of IndividualDeliberation were identical to those from Individual. Instructions for Part 2 were identical to individual, except that we added a sentence informing subjects that they have the option to write down their thoughts: "Part 2 is identical to Part 1, except that you have now the possibility to write down your thoughts.” and an additional screen (see below) explaining how to write down one’s thoughts.]

Procedures

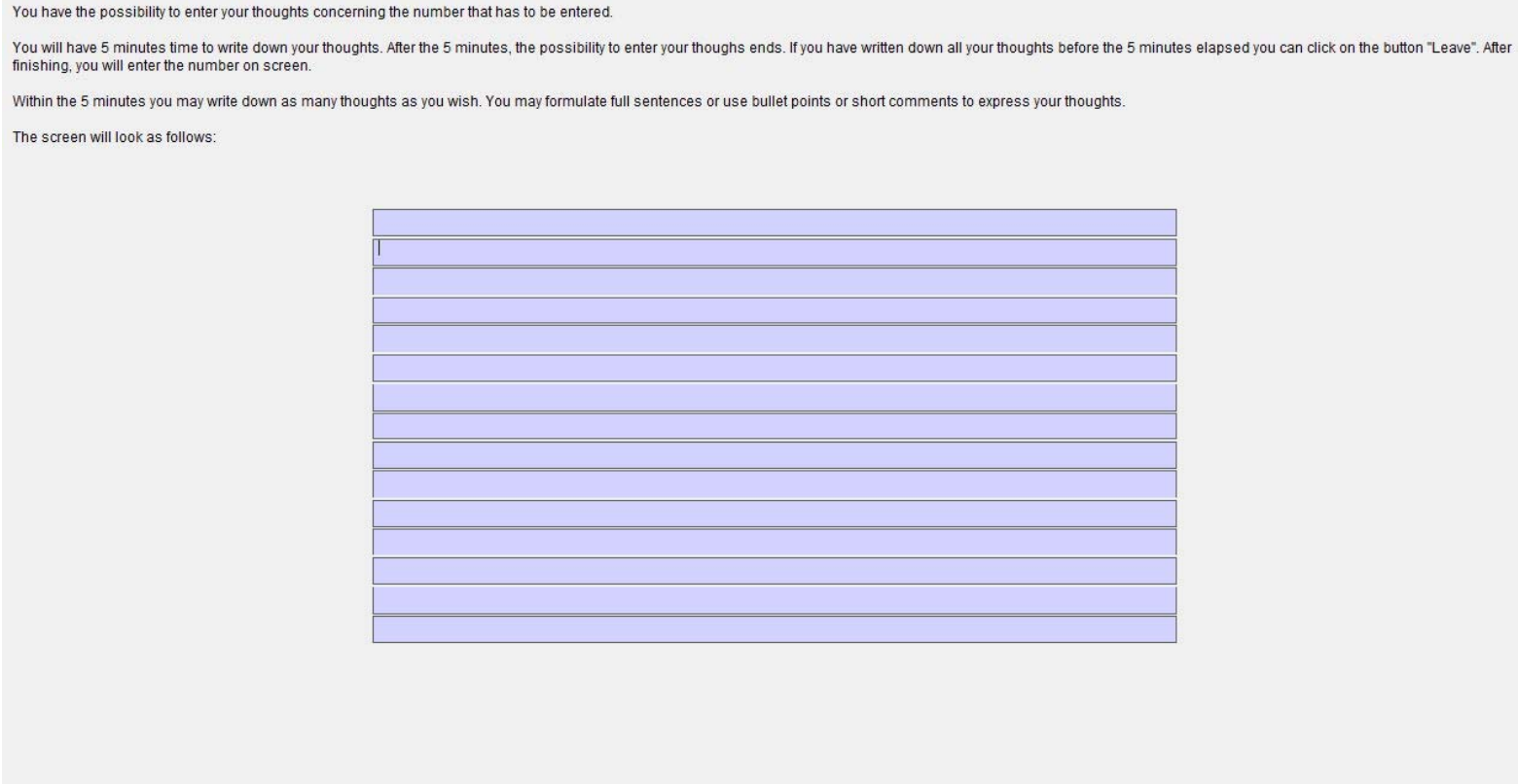




\section{D - Codebook: Variables for the chat analysis}

Appendix D includes the codebook that was used by our coders.

\section{- Chat in general}

o Duration (\# of seconds) (duration)

$0 \quad$ \# of messages (messages)

0 Average length of a message (\# of characters, incl. spaces) (average_length)

\section{- Content}

Which arguments are being made to persuade other group members? How often are they alluded to during the entire chat? ONLY COUNT ARGUMENTS THAT ARE EXPLICITLY MENTIONED (e.g. if "๑" was displayed and participant says "I think we should be honest and should enter $\odot$ " $\rightarrow$ honesty=1, "I think we should enter $\odot$ " $\rightarrow$ honesty=0)

o Money discussed in favor of lying (\# of times money/points/payoffs are mentioned as an argument) (argument_money_lie)

Example: We should enter 5 because it will maximize our payoffs

o Money discussed in favor of honesty (\# of times money/points/payoffs are mentioned as an argument) (argument_money_hon)

Example: We should enter 3, it will still give us 6 euros

o Honesty discussed in favor of honesty (\# of times mentioned)

(argument_honesty_hon)

Example: Let's be honest

o Honesty discussed in favor of lying (\# of times mentioned) (argument_honesty_lie) Example: There is no need to be honest

o Refer to misunderstanding/insecurity concerning the task in favor of lying (\# of times mentioned) (argument_insecurity_lie)

Example: I am uncertain about the task, I thought we can enter any number we want to enter

o Refer to misunderstanding/insecurity concerning the task in favor of honesty (\# of times mentioned) (argument_insecurity_hon)

Example: I am uncertain about the task, I thought we have to enter the number we saw

o Discuss that "we should stick to the rules "\# of times mentioned) (argument_rules_yes)

o Discuss that "we do not have to stick to the rules" (\# of times mentioned) (argument_rules_no)

o Reference to honesty of others outside the group (e.g. experimentator, people in general, other participants, ...) (\# of times mentioned) (argument_others_honest)

o Reference to dishonesty of others outside the group (e.g. experimenter, people in general, other participants, ...) (\# of times mentioned) (argument_others_dishonest)

o Refer to positive consequences (\# of times mentioned) (consequences_pos)

o Refer to negative consequences (\# of times mentioned) (consequences_neg) 


\section{References for Online Appendix}

Foerster, A., Pfister, R., Schmidts, C., Dignath, D., Kunde, W., 2013. Honesty saves time (and justifications). Frontiers in Psychology, 4, 1-2.

Shalvi, S., Eldar, O., Bereby-Meyer, Y., 2012. Honesty requires time (and lack of justifications). Psychological Science, 23, 1264-1270.

Shalvi, S., Eldar, O., Bereby-Meyer, Y., 2013. Honesty requires time-a reply to Foerster et al.(2013). Frontiers in Psychology, 4, 1-2.

Van't Veer, A., Stel, M., van Beest, I., 2014. Limited Capacity to Lie: Cognitive Load Interferes with Being Dishonest. Judgment and Decision Making, 9, 199-206. 